UNIVERSIDADE DE SÃO PAULO

FACULDADE DE ODONTOLOGIA DE RIBEIRÃO PRETO

KARLA CRISTIANE VIEIRA DA FONSECA

Estabilidade de cor de cerâmicas odontológicas submetidas ao processo de envelhecimento artificial acelerado após múltiplos ciclos de queima 


\section{Estabilidade de cor de cerâmicas odontológicas submetidas ao processo de envelhecimento artificial acelerado após múltiplos ciclos de queima}

Dissertação apresentada à Faculdade de Odontologia de Ribeirão Preto, da Universidade de São Paulo, para a obtenção do Título de Mestre em Odontologia.

Área de concentração: Reabilitação Oral Orientadora: Prof ${ }^{a}$. Dr ${ }^{a}$. Fernanda de Carvalho Panzeri Pires de Souza 
AUTORIZO A REPRODUÇÃO E DIVULGAÇÃO TOTAL OU PARCIAL DESTE TRABALHO, POR QUALQUER MEIO CONVENCIONAL OU ELETRÔNICO, PARA FINS DE ESTUDO E PESQUISA, DESDE QUE CITADA A FONTE.

FICHA CATALOGRÁFICA

Fonseca, Karla Cristiane Vieira da

Estabilidade de cor de cerâmicas odontológicas submetidas ao processo de envelhecimento artificial acelerado após múltiplos ciclos de queima. Ribeirão Preto. FORP - USP, 2005.

Dissertação apresentada à Faculdade de Odontologia de Ribeirão Preto / USP, Área de concentração: Reabilitação Oral.

Orientadora: Souza, Fernanda de Carvalho Panzeri Pires de

Unitermos: Estabilidade de cor, cerâmica, envelhecimento artificial acelerado, espectrofotômetro, metalocerâmica, livre de metal 


\section{FOLHA DE APROVAÇÃO}

Karla Cristiane Vieira da Fonseca

Estabilidade de cor de cerâmicas odontológicas submetidas ao processo de envelhecimento artificial acelerado após múltiplos ciclos de queima

Dissertação apresentada à Faculdade de Odontologia de Ribeirão Preto, da Universidade de São Paulo, para a obtenção do Título de Mestre em Odontologia.

Área de concentração: Reabilitação Oral

Aprovado em:

\section{Banca Examinadora}

Prof. Dr.

Instituição: Assinatura:

Prof. Dr.

Instituição: Assinatura:

Prof. Dr.

Instituição: Assinatura: 


\section{Dedico este trabalho àqueles que amo:}

À minha família, por estar sempre presente em todos os momentos e conquistas.

À minha irmã Karen por seu apoio incondicional que me possibilitou vivenciar esta experiência.

À minha mãe Nair por sua ajuda preciosa que me permitiu concluir esta etapa com serenidade.

Ao meu marido Wilson por seu amor e compreensão neste período em que ficamos afastados para que eu pudesse concluir este trabalho.

Ao meu filho Matheus, razão da minha vida, por seu olhar e abraço amáveis, e pelo seu sorriso lindo. 


\section{AGRADECIMENTOS ESPECIAIS}

Aे Deus, o Criador de todas as coisas.

À minha orientadora Profa. Dra. Fernanda de Carvalho Panzeri Pires de Souza por ter me acolfido e orientado durante este período, por ter enriquecido meu amadurecimento profissional $e$ pessoal, por seus conselhos e apoio em momentos difíceis, por sua valiosa ajuda que permitiu a conclusão deste trabalho. Obrigada pelo seu empenho e amizade. 


\section{AGRADECIMENTOS}

À minha amiga Alessandra pela amizade, pela contribuição com a minha escolha por esta Instituição de Ensino, e por ter acompanhado todos os passos desta experiência de vida.

Aos meus colegas pela amizade que cultivamos neste período de convivência.

Aos funcionários do Departamento de Materiais Dentários e Prótese e do Laboratório Integrado de Pesquisa em Biocompatibilidade de Materiais (LIPEM) na Faculdade de Odontologia de Ribeirão Preto da Universidade de São Paulo, pela agradável convivência e pela disposição em colaborar com a execução deste trabalho.

Aos professores do Departamento de Materiais Dentários e Prótese, na Faculdade de Odontologia de Ribeirão Preto da Universidade de São Paulo, pela contribuição na ampliação dos meus confecimentos e crescimento científico. 


\section{RESUMO}

FONSECA, K. C. V. Estabilidade de cor de cerâmicas odontológicas submetidas ao processo de envelhecimento artificial acelerado após múltiplos ciclos de queima. 2005. f. Dissertação (Mestrado) - Faculdade de Odontologia de Ribeirão Preto, Universidade de São Paulo, Ribeirão Preto, 2005.

A estética tornou-se de fundamental importância nas últimas décadas, fazendo com que houvesse uma grande evolução nos materiais dentários e técnicas restauradoras para atender a esta exigência. As cerâmicas odontológicas são materiais estéticos e biocompatíveis, podendo ser uma ótima alternativa quando aplicadas a casos apropriadamente selecionados. O sucesso estético de uma restauração de cerâmica depende da caracterização de superfície, da integridade marginal, da forma anatômica e da coloração. $O$ presente estudo teve - objetivo de avaliar a estabilidade de cor de dois tipos de restaurações em cerâmica odontológica, metalocerâmica e livre de metal, submetidas a múltiplos ciclos de queimas. Foram realizados 60 corpos-de-prova, sendo 30 na forma de metalocerâmicas e 30 livres de metal que foram divididas em três grupos de 10 amostras cada, sendo confeccionadas em duas, três e quatro queimas respectivamente. As leituras de cor foram realizadas em espectrofotômetro $P C B$ 6807 BYK GARDNER antes e após envelhecimento artificial acelerado (Comexim Matérias Primas). Analisando-se inicialmente a influência do número de queimas sobre a cor da cerâmica odontológica, houve diferenças estatisticamente significantes para as coordenadas $L^{*}$ nas amostras metalocerâmicas, sendo que 0 grupo de 3 queimas foi o que apresentou diferenças em relação aos outros dois grupos. Para as amostras livres de metal, houve diferenças nas coordenadas $L^{*}$, $a^{*} e b^{*}$, com comportamentos heterogêneos para as 3 coordenadas. Os resultados indicaram diferenças estatisticamente significantes na variação total de cor $(\Delta E)$ para as amostras de 3 queimas, comparando-se os tipos de restauração. Quando analisada a interferência do número de queimas de um mesmo tipo de restauração, não houve diferença estatisticamente significante para a amostra livre de metal. Para a amostra metalocerâmica, houve apenas diferença estatisticamente significante entre as amostras que receberam 2 e 3 queimas. Para a variação total nas coordenadas $L^{*}, a^{*} e b^{*}$ também houve variação de valores para os dois tipos de amostras e em relação aos ciclos de queimas. Concluiu-se que as pequenas diferenças estatisticamente significantes encontradas em alguns grupos são invisíveis e sem qualquer significado clínico $(\triangle E<3,3)$. Além disso, os múltiplos ciclos de queima e o envelhecimento acelerado não modificaram de forma significativa a estabilidade de cor da cerâmica nas formas em que foram empregadas $(\Delta<1)$. 
Palavras-chave: Estabilidade de cor, cerâmica, envelhecimento artificial acelerado, espectrofotômetro, metalocerâmica, livre de metal 


\begin{abstract}
Esthetics has become essential over the past few decades, causing dental materials and restorative techniques to evolve significantly. Dental ceramics are esthetic and biocompatible materials which may be an excellent alternative for properly selected cases. The esthetic success of a ceramic's restoration depends on surface characterization, marginal integrity, anatomic form, and color. This study aimed to assess the color stability of two types of dental ceramic restorations, metalloceramic and metal-free, submitted to multiple burn cycles. Sixty specimens were fabricated: 30 metalloceramic and 30 metal-free. The specimens were divided into 3 groups $(n=10)$ according to the number of burns (2, 3, and 4 burns). Color readings were performed using a PCB 6807 BYK GARDNER spectrophotometer before and after artificial accelerated aging (Comexim Raw Materials). By analyzing the influence of the number of burns over the dental ceramic's color, statistically significant differences were found for the coordinate $L^{*}$ for the metalloceramic specimens, in the group of 3 burns, in relation to the other 2 groups. For the metal-free specimens, there were differences for the coordinates $L^{*}, a^{*}$, and $b^{*}$, with heterogeneous compartments for the 3 coordinates. The results revealed statistically significant differences for total color variation $(\Delta E)$ for the 3 burns group, in comparison to the other types of restoration. When analyzing the specimens of a single type of material, in terms of the interference of the number of burns, the metal-free samples showed no statistically significant differences, whereas the metalloceramic samples showed difference only between those that received 2 and 3 burns. For the total variation of coordinates $L^{*}, a^{*}$, and $b^{*}$, both materials showed a variation in those values and in relation to burn cycles. The small statistically significant differences found in some groups are invisible and present no clinical meaning $(\Delta E<3.3)$. In addition, the multiple burn cycles and accelerated aging did not modify significantly the ceramic's color stability $(\Delta<1)$.
\end{abstract}

Key words: 1. color stability, 2. ceramics, 3. artificial accelerated aging, 4. spectrophotometer, 5. metalloceramics, 6. metal-free. 


\section{SUMÁRIO}

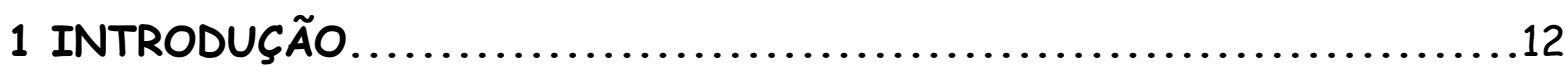

2 REVISÃO BIBLIOGRÁFICA ......................................

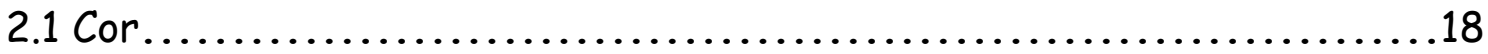

2.2 Análise instrumental da cor.................................25

2.3 Influência do número de ciclos de queima na estabilidade de cor das cerâmicas odontológicas..........................................26

2.4 Influência da infra-estrutura metálica na estabilidade de cor de cerâmicas odontológicas..........................................31

2.5 Envelhecimento artificial acelerado.............................39

3 PROPOSIÇÃO .................................................... 43

4 MATERIAL E MÉTODOS............................................ 45

4.1 Material ................................................. 46

4.2 Método......................................................47

4.2.1 Confecção da matriz......................................47

4.2.2 Confecção dos corpos-de-prova livres de metal................48

4.2.3 Confecção dos discos metálicos correspondentes às infraestruturas................................................. 50

4.2.4 Confecção dos corpos-de-prova metalocerâmicos................51

4.2.5 Acabamento dos corpos-de-prova.........................53 
4.2.7 Análise espectrofotométrica da cor dos corpos-de-prova antes e após o processo de envelhecimento artificial acelerado...................54

4.2.8 Processo de Envelhecimento Artificial Acelerado................56

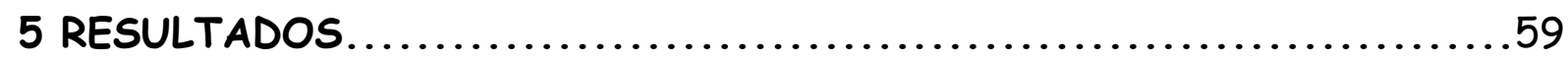

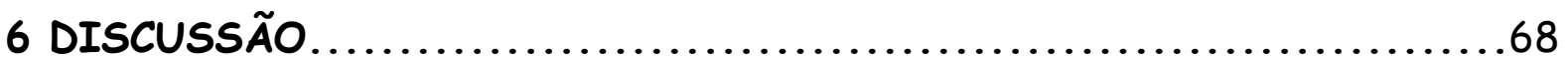

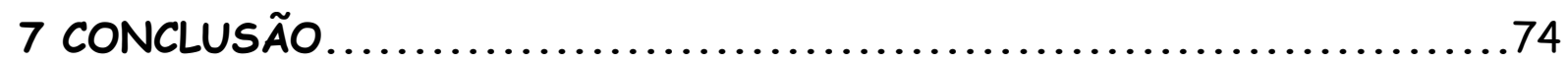

8 REFERÊNCIAS BIBLIOGRÁFICAS ................................... 
INTTRODUÇÃ 


\section{INTRODUÇÃO}

A estética tornou-se de fundamental importância e a busca por materiais estéticos e técnicas restauradoras e/ou reabilitadoras que tornem as restaurações com aparência mais próxima ao natural tem sido alvo dos esforços tanto dos cirurgiões-dentistas como dos fabricantes de materiais dentários. $O$ fato das restaurações metálicas convencionais serem rejeitadas devido a sua aparência negativa, e até restaurações em resina composta, principalmente em dentes anteriores, como consequiência de sua estética inferior e menor durabilidade quando comparadas a uma cerâmica, faz com que cada vez mais as restaurações indiretas em cerâmica sejam requisitadas.

Por décadas o objetivo das restaurações em dentes anteriores tem sido de repor a estrutura dentária perdida por doença de uma maneira estética (HEYDECKE et al., 2001). Aperfeiçoamentos das técnicas e materiais dentários nos últimos 15 anos conduziram ao desenvolvimento das facetas de porcelana (PEUMANS et al., 2000), que servem bem para a mudança da forma e cor dos dentes (FAUNCE, 1983; NIXON, 1996; BELSER et al., 1997; MCLAUGHLIN, 1998). Pesquisas clínicas demonstraram que a taxa de sucesso global das restaurações em faceta são muito altas (FRADEANI, 1998; KIHN ; BARNES, 1998; PEUMANS et al., 2000).

A cerâmica é um material estético e biocompatível que pode ser uma ótima alternativa quando aplicada a casos apropriadamente selecionados (MOLIN; 
KARLSSON, 1992). Sua estabilidade de cor tem se mostrado excelente em estudos que avaliaram diferentes sistemas cerâmicos, sendo eles de cerâmica pura ou aplicada ao metal (MULLA; WEINER, 1991; MOLIN; KARLSSON, 1992; MILLEDING et al., 1995; SJÖGREN et al., 1995; TIDEHAG; GUNNE, 1995; MILLEDING et al., 1998; MUTLU-SAGENSEN et al., 2001).

O sucesso estético de uma restauração de porcelana depende de vários fatores como a caracterização da superfície, integridade marginal, forma anatômica e a coloração (MEIJERING et al., 1997). Clinicamente, uma combinação de cores adequada é aspecto importante em qualquer restauração dentária estética. De acordo com o resultado de alguns estudos, a combinação final de cores de coroas de porcelana em relação à dentição natural adjacente continua problemática (MILLEDING et al., 1998; HASELTON et al., 2000).

$\mathrm{Na}$ prática clinica, o processo de replicação da cor para porcelana dental constitui-se de uma fase de seleção da tonalidade seguida pela duplicação da mesma. A seleção da tonalidade pode ser feita pelo método visual, através do uso da escala de cores, ou pelo método instrumental através do uso do colorímetro ou espectrofotômetro (WEE et al., 2002). A seleção visual da tonalidade é o método mais comum de determinação da cor segundo Van Der Burgt et a (1990), porém a duplicação da cor por este processo é marcada por resultados não confiáveis e inconsistentes (CULPEPPER, 1970; OKUBO et al., 1998). Vários trabalhos descreveram as inadequações das escalas de cores dentais em termos de 
extensão e distribuição espacial da cor no dente (SPROULL, 1973; PRESTON, 1985; MILLER, 1987; O’ BRIEN et al., 1991; FERREIRA; MONARD, 1991).

A análise instrumental da coloração oferece um potencial avanço quando comparada com a determinação visual da cor, leituras instrumentais são objetivas, confiáveis e mais rapidamente obtidas. $O$ uso extensivo de colorímetros computadorizados e espectrofotômetros são relatados na pesquisa odontológica (BREWER et al., 1985; GOODKIND et al., 1985; GOODKIND; SCHWABACHER, 1987; JOHNSTON; KAO, 1989; BREWER et al., 1990; BREWER et a., 1991; ISHIKAWA-NAGAI et al., 1992; ISHIKAWA-NAGAI et al., 1993; ISHIKAWA-NAGAI et al., 1994; OKUBO, 1998).

Erros associados com a duplicação da tonalidade da porcelana dental são bem documentados. Estes erros são relacionados ao metal subjacente usado (CRISPIN et al., 1991; O'NEAL et al., 1987; STAVRIDAKIS et al., 2000; STAVRIDAKIS et al., 2004), à porção de pó da porcelana (O'BRIEN et al., 1991), e à marca comercial da porcelana (SEGHI et al., 1986; ROSENSTIEL; JOHNSTON, 1988; O'BRIEN et al., 1991; GROH et al., 1992). Também outros fatores como o número de ciclos de queima (BARGHI; GOLDBERG, 1977), a temperatura de cocção (MULLA; WEINER, 1991; MUTLU-SAGESEN et al., 2001; WEE et al., 2002), e o método de condensação do material podem influenciar na coloração (EVANS et al., 1990). 
Quanto ao número de ciclos de queima, segundo Barghi e Golberg (1977), as primeiras cinco queimas das porcelanas, com e sem a utilização de vácuo, não apresentaram diferenças na coloração, nas queimas subseqüentes pequenas diferenças puderam ser observadas.

Entretanto, pouco se sabe a respeito das modificações na cor das restaurações cerâmicas em função do tempo de uso. Muitos trabalhos enfocam as modificações nas propriedades mecânicas do material, porém, as condições da cavidade bucal são adversas e muitas são as formas de construção de uma restauração cerâmica. 
REVISÃO BIBLIOGRÁFICA 


\section{REVISÃO BIBLIOGRÁFICA}

\section{$2.1 \mathrm{COR}$}

Muitos são os fatores considerados com relação à estética na odontologia restauradora e reabilitadora como a forma e tamanho dos dentes, caracterizações de superfície compreendidas pelas pigmentações e presença de sulcos e a cor. A cor é um fator de grande importância quando se está avaliando a estética, pois uma restauração com coloração diferente a dos dentes naturais adjacentes chama muito a atenção. A cor é um fator complexo de ser explicado $e$ compreendido. Mais complexo ainda é conseguir a reprodução exata da cor dos dentes naturais em restaurações dentárias, pois existem diversos fatores envolvidos neste processo.

Muitos sistemas de ordenação de cores estão disponíveis. Segundo Spoull (2001), o Sistema de Ordenação de Cores de Munsell deveria ser o sistema de escolha para a combinação de cores na Odontologia devido a sua consistência, flexibilidade e simplicidade.

O sólido de cores de Munsell (Figura 01) pode ser comparado com uma esfera ou um cilindro, sendo ele uma figura tri-dimensional irregular que tem características de ambos (JUDD; WYSZECKI, 1963; NICKERSON, 1946; SPROULL, 2001). 


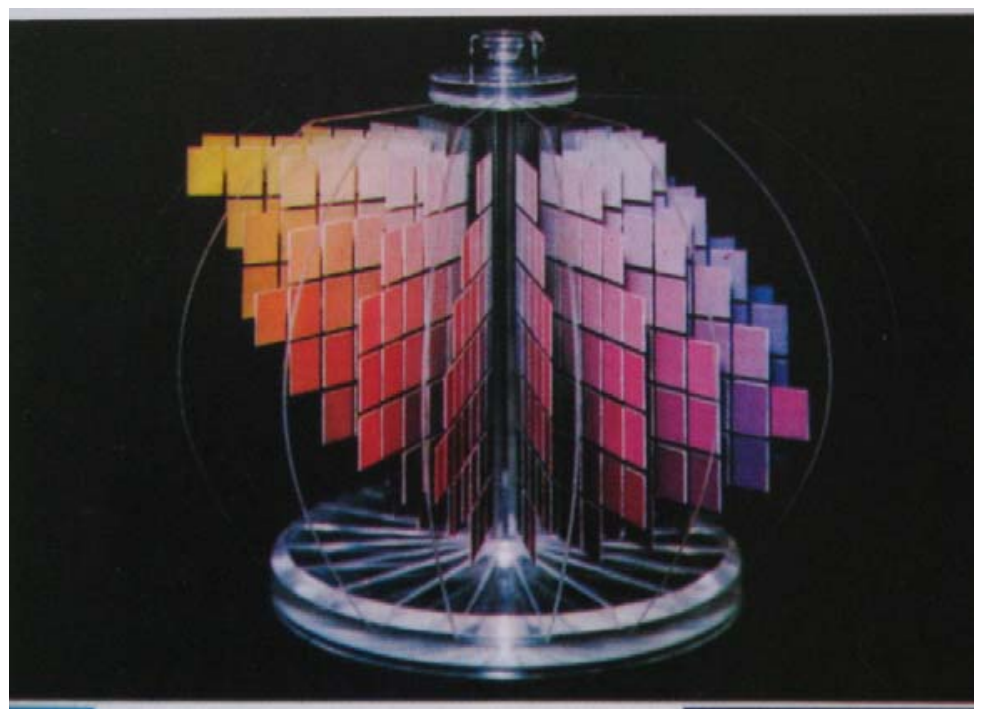

Figura 01 - Sólido de cores de Munsell

Segundo Munsell, as dimensões da cor são compreendidas por matiz, valor e croma, que são importantes no trabalho com a cor para entender a fundo o seu conceito tri dimensional (CLARK, 1931). O matiz é a primeira dimensão da cor, a mais fácil de entender, é a qualidade na qual distinguimos uma família de cor da outra, como o vermelho do amarelo, o verde do azul ou roxo. Para se referir a um matiz no Sistema de Munsell, utilizam-se as seguintes iniciais: $R$ para o vermelho, YR para o amarelo - vermelho, Y para o amarelo e assim por diante. Cada matiz é dividido em dez segmentos, visualmente espaçado um do outro de forma semelhante.

Valor e croma são mais difíceis de entender e são confundidos um com o outro. Especial atenção deve ser focada nestas dimensões. O valor é a qualidade através da qual distinguimos uma cor clara de uma cor escura, e isto é relacionado ao eixo polar acromático que vai de uma extremidade a outra do 
sólido de cores de Munsell. O valor de uma cor é determinado por qual cinza, na escala de valores, ela se assemelha em luminosidade / escuridão. Ao puro preto da escala de valores é atribuído o valor zero, ao puro branco o valor dez. Um infinito número de graduações de cinza é possível na medida em que se vai do preto para o branco, mas apenas nove graus de cinza são utilizados no Sistema de Munsell. Baixos valores se referem a cores escuras, altos valores a cores claras. O croma é a última dimensão da cor, é a qualidade através da qual distinguimos uma cor forte de uma cor fraca; a intensidade de um matiz característico; a intensidade da cor. As graduações do croma são referentes aos raios da roda.

A notação usada no Sistema de Munsell menciona primeiramente o matiz, que é colocado na esquerda; o valor é colocado acima da linha inclinada e a direita do símbolo do matiz sendo expresso por um número; e o croma também expresso por um número é colocado à direita da linha inclinada. O formato de uso comum é $H V / C . O H$ é precedido por um número para indicar a subdivisão precisa do matiz. Esta designação fornece a identificação exata de uma cor que é compreendida internacionalmente (CLARK, 1931).

A Commission Internationale de l'Éclairage (CIE), uma organização devotada à padronização em áreas como a cor e aparência, definiu em 1931 uma fonte de luz padrão, desenvolveu um padrão de observação e possibilitou o cálculo dos valores de tridimensão, que representam como o sistema visual humano responde a uma dada cor (MCLAREN, 1987). 
Em 1976, o CIE definiu o universo da cor, CIE Lab, que suporta a teoria aceita de que a percepção da cor é baseada em três receptores de cor separados nos olhos (vermelho, verde e azul), e é um dos mais populares universos da cor em vigor. O CIE Lab representa um universo da cor uniforme, com distâncias equivalentes correspondendo a uma semelhante percepção das diferenças de cor. Neste universo de cor tridimensional, os três eixos são $L^{*}, a^{*}$ e $b^{\star}$. $O$ valor $L^{*}$ é a medida da luminosidade de um objeto e é quantificado em uma escala na qual o preto puro tem valor de $L^{*}$ igual a zero e valor de $L^{*}$ igual a 100 para um reflexo completamente dissipado (branco puro). $O$ valor de $a^{\star}$ é a medida da quantidade de vermelho ( $a^{\star}$ positivo) ou verde ( $a^{\star}$ negativo). O valor de $b^{\star}$ é a medida da quantidade de amarelo ( $b^{\star}$ positivo) ou azul ( $b^{\star}$ negativo). As coordenadas $a^{\star} e b^{\star}$ aproximam-se de zero para cores neutras (branco, cinza) e aumentam de magnitude para cores mais saturadas ou intensas (Figura 02). A vantagem do sistema CIE Lab é que as diferenças de cores relatadas pela percepção visual e significância clínica podem ser expressas em unidades (O'BRIEN, 1997). 


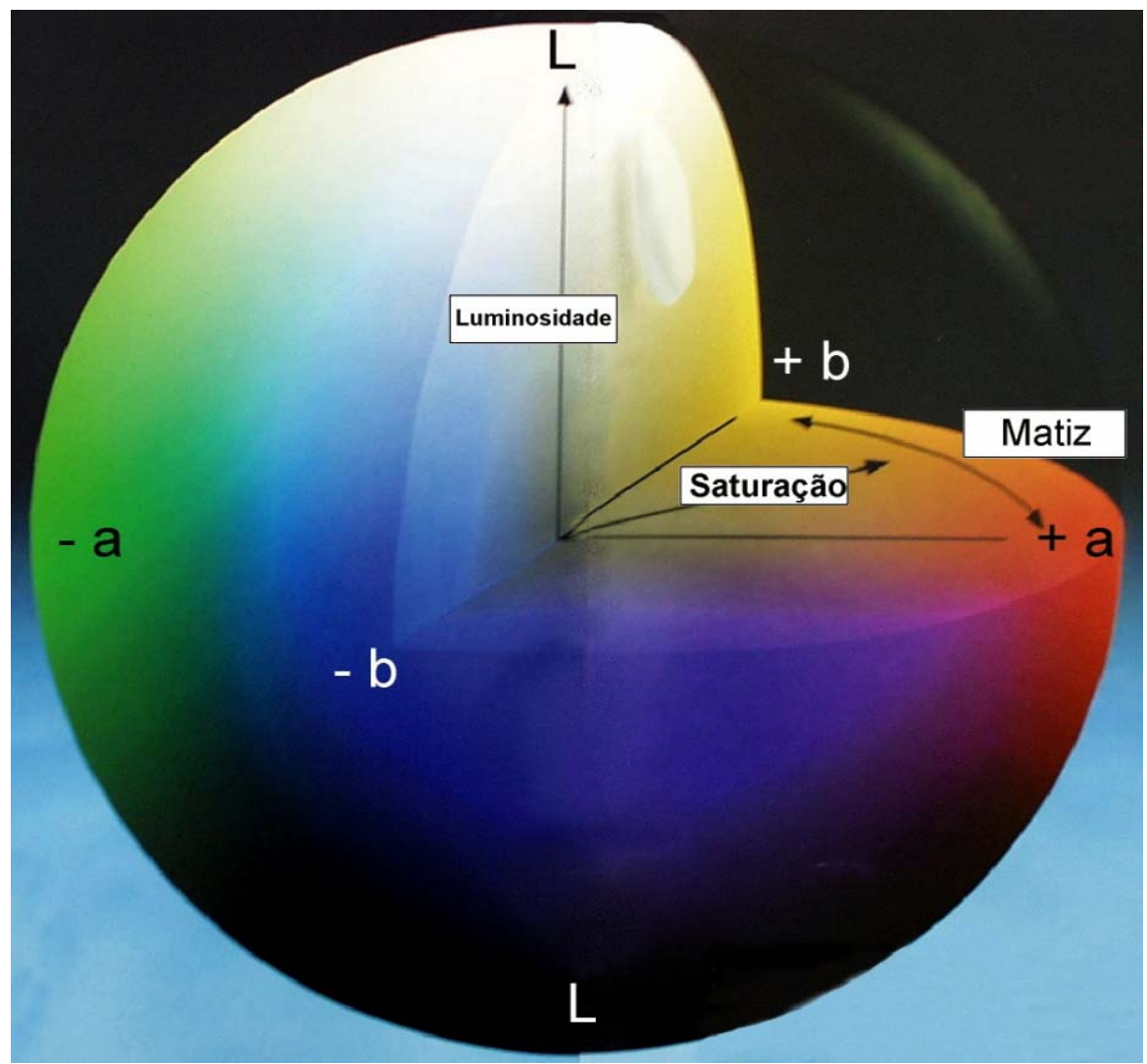

Figura 02 - Sistema de coordenadas de cores CIE $L^{\star} a^{\star} b^{\star}$.

Joiner (2004), relata em seu estudo que o fenômeno da cor é uma resposta psicofísica à interação física da energia da luz com um objeto, e a experiência subjetiva individual de um observador. Segundo o autor, três fatores podem influenciar a percepção da cor: a fonte de luz, o objeto que está sendo observado e o observador que está vendo o objeto. A fonte de luz pode emitir energia radiante com comprimento de onda variável e isto é caracterizado pela relativa quantidade de energia emitida em cada comprimento de onda em um espectro visível. A fonte de luz que ilumina um objeto afeta a percepção da cor, já que fontes individuais contêm quantidades variáveis de luz em cada comprimento de onda. A refletância espectral de um objeto caracteriza a cor que o compõe. Por 
exemplo, um objeto vermelho parece vermelho primeiramente porque reflete comprimentos de onda vermelhos mais do que verdes e azuis. $O$ principal problema freqüentemente surge quando da tentativa de comunicar a cor para outros.

Na prática clínica, o processo de replicação da cor para a porcelana é composto por uma fase de seleção do tom seguida por sua duplicação, executada durante a confecção da restauração no laboratório de prótese. Muitos métodos são atualmente usados para determinar a cor dos dentes. Estes variam a partir da comparação visual subjetiva utilizando papel, porcelana ou escalas de cores de resina acrílica até mensurações instrumentais objetivas utilizando-se espectrofotômetros, colorímetros e técnicas computadorizadas de análise de imagens.

A determinação visual da cor através da comparação dos dentes com escalas de cores padrão é o método mais freqüentemente aplicado na odontologia (VAN DER BURGT et al., 1990). Essas escalas de cores definem as aplicações práticas da organização da cor. Este é um processo subjetivo através do qual os dentes e a escala de cores são observados simultaneamente sob as mesmas condições de luminosidade. $O$ dentista deve decidir qual dos padrões oferece a cor mais aceitável para igualar com os dentes ou dente em questão e se esta irá contentar o paciente. 
Quanto melhor a escala de cores, melhor é a chance de sucesso quando a população total dos que usam este método é considerada. Wee et al. (2002), relatou que o sucesso na combinação de cores é um importante aspecto clínico em qualquer restauração estética.

De acordo com estudos clínicos (MILLEDING, 1998; BERGMAN, 1999; SJÖGREN, 1999; HASELTON, 2000), a combinação final de cores de coroas de porcelana à dentição natural adjacente continua problemática. $O$ sucesso ou falha deste procedimento está intimamente relacionado com a adequação da escala de cores, juntamente com a familiarização do dentista com os procedimentos básicos de combinação de cores (SPROULL, 2001). Culpepper (1970), salientou as discrepâncias individuais entre os dentistas em combinar tonalidades dos dentes naturais e a inabilidade de alguns em duplicar suas próprias combinações selecionadas.

Variáveis gerais como condições externas de luz, experiência, idade, fadiga do olho humano e variáveis psicológicas que podem levar a inconsistências (WATTS; ADDY, 2001; HILL, 1987). Segundo Culpepper (1970), alguns dos erros na combinação das cores devem ser atribuídos às variáveis humanas sempre presentes, mas outros erros como ele salientou devem ser atribuídos à inadequação das escalas de cores disponíveis.

Os requisitos primordiais para qualquer escala de cores incluem um arranjo lógico e uma distribuição adequada no universo da cor dos dentes naturais. Uma 
escala de cores baseada em algum sistema de ordenação de cores pode preencher estes requisitos (BRIDGEMAN, 1987).

Apesar de suas limitações, o uso das escalas de cores é um método rápido e com custo - benefício para a mensuração das cores dos dentes. A habilidade dos indivíduos em distinguir a cor dos dentes pode ser aperfeiçoada com treinamento e experiência (WATTS; ADDY, 2001; RAGAIN et al., 2000).

\subsection{ANÁLISE INSTRUMENTAL DA COR}

De acordo com Joiner (2004), instrumentos como os espectrofotômetros e colorímetros têm sido usados na indústria e no cenário das pesquisas para as mensurações de cor de uma ampla variedade de materiais e substratos. Os espectrofotômetros medem um comprimento de onda por tempo a partir da refletância ou transmissão de um objeto. Entretanto, Tung et al. (2002), relataram que o uso difundido de espectrofotômetros na pesquisa odontológica e no ambiente clínico tem sido retardado pelo fato de o equipamento ser complexo e caro e, mais importante, por ser difícil de fazer a mensuração de cor dos dentes in vivo com este equipamento.

Os colorímetros têm filtros de cor que aproximam a função espectral dos olhos do observador padrão e são geralmente designados para medir a cor em termos de estímulos tridimensionais $X, Y, Z$ ou em valores do CIE Lab (VAN DER BURGT et al., 1990; TUNG et al., 2002). 
As desvantagens do uso de colorímetros para a mensuração da cor de dentes incluem que o instrumento é designado para a medição de superfícies planas e lisas, e os dentes não são planos nem lisos podendo possuir anomalias na superfície; além disso, os colorímetros com aberturas pequenas são propensos a uma significativa perda de efeitos nas margens, então a determinação da cor estará sujeita a erros (VAN DER BURGT et al., 1990; BOLT et al., 1994).

Segundo Douglas (1997), a principal aplicação da colorimetria instrumental envolve a exploração da sua sensibilidade de detecção e de mensuração de pequenas diferenças de cor entre amostras de cor similares, já que a mensuração diferencial é altamente reproduzível entre instrumentos e representa o uso mais efetivo da avaliação colorimétrica.

\subsection{INFLUÊNCIA DO NÚMERO DE CICLOS DE QUEIMA NA}

\section{ESTABILIDADE DE COR DAS CERÂMICAS ODONTOLÓGICAS}

As restaurações e próteses fixas confeccionadas em cerâmica pura e metalocerâmica são os tratamentos de escolha da atualidade, por serem mais estéticos devido a sua capacidade de imitar a coloração da dentição natural adjacente. $O$ problema em conseguir que estas restaurações simulem a coloração dos dentes naturais se deve a diversos fatores começando pelas escalas de cores disponíveis que possuem uma série de inadequações, a capacidade do profissional em selecionar a cor adequada, aos muitos fatores envolvidos na fase laboratorial 
de confecção da peça e, dentro destes fatores, está o alvo da pesquisa que é a influência do número de ciclos de queima na mudança da cor originalmente escolhida para restaurações cerâmicas.

Barghi e Goldberg (1977), realizaram um estudo em que foram confeccionadas amostras de porcelana queimada a vácuo ou não, variando o número de queimas de 1 a 10. Após a confecção das amostras foi realizada a analise das variações na cor, valor e croma sob luz natural e luz artificial através do método visual, realizado por sete observadores. Os autores verificaram que não houve diferença de cor detectada nas primeiras cinco queimas das porcelanas queimadas com e sem vácuo. Pequenas mudanças foram observadas nas queimas subseqüentes. Estas mudanças de cor foram mais visiveis nas amostras queimadas sem vácuo do que nas queimadas com vácuo. Todavia, as mudanças na coloração das porcelanas após múltiplas queimas não foram suficientemente significativas para causar a rejeição das amostras. Segundo estes autores, a tonalidade das porcelanas permanecerá estável, com as múltiplas queimas, desde que o procedimento de cocção seja cuidadosamente executado.

Jorgenson e Goodkind (1979), realizaram um estudo no qual foram confeccionadas 125 amostras metalocerâmicas. Utilizaram a liga semipreciosa SMG - W sobre a qual construíram cinco amostras das porcelanas Ceramco nas cores A3, B2 e D3; Vita na cor B2 e Biobond na cor B62. Confeccionaram as amostras com espessuras de 1, 2 e $3 \mathrm{~mm}$ para cada cor, sendo que estas foram 
queimadas por duas vezes. As amostras com $2 \mathrm{~mm}$ de espessura receberam mais dois grupos, também com 5 amostras cada, que foram queimados por 5 e 10 vezes. Cada amostra teve sua cor analisada pelo espectrofotômetro e os dados obtidos foram expressos na terminologia CIE Lab e convertidos para a notação de Munsell para a avaliação das dimensões da cor (matiz, croma e valor) no que diz respeito às diferenças de tonalidade, espessura da porcelana e número de queimas. Os autores concluíram que o repetido número de queimas não afetou a estabilidade de cor de nenhuma das cores testadas; que a espessura da porcelana afetou significativamente a cor, sendo que o aumento na espessura possibilitou melhores resultados $e$, por este motivo, o maior desgaste do dente sem violar a integridade pulpar é encorajado; todas as cores da porcelana Ceramco testadas tiveram estabilidade de cor comparável. Quanto às dimensões da cor, o matiz foi a dimensão menos significativa, pois nas amostras testadas este ocupou uma porção muito pequena da extensão do matiz em dentes naturais. $O$ croma, sem dúvida mais crítico que o matiz, não teve uma diferença tão significativa de um tom para outro, com exceção para a cor D3 da porcelana Ceramco. A extensão do valor para todas as amostras não cobriu suficientemente a extensão do valor para os dentes naturais. Isto foi especialmente verdadeiro para baixos valores. Entretanto, pequenas mudanças no valor das amostras foram significativas para as espessuras das porcelanas e diferentes tons, com exceção para as cores $A 3$ e D3 da porcelana Ceramco. 
Barghi (1982), utilizou quatro marcas comerciais de cerâmica - VMK-68, Ceramo, Neydium, Will Ceram e cinco tipos de ligas metálicas preciosas - SMG-2, Bak-on, Will Ceram, Jelenk "O" e UTK - e a liga metálica não preciosa Unibond. Cento e oito amostras foram confeccionadas e divididas em seis grupos de 18, um grupo para cada um dos seis tipos de ligas utilizadas. Todas as amostras de ligas receberam uma camada de opaco de $0,5 \mathrm{~mm}$ de espessura, sobre a qual foi aplicada uma camada de $1 \mathrm{~mm}$ de porcelana queimada de acordo com as instruções de cada fabricante. As 18 amostras de cada grupo foram divididas em nove subgrupos com 3 amostras cada, que foram glazeados de uma a nove vezes. As amostras do último subgrupo, de número nove, receberam tempo adicional na temperatura do glazeamento para alcançar um glaze ótimo. Após a confecção as amostras, foram posicionadas em um quadro para a comparação visual das tonalidades que foi realizada por sete observadores. Como resultado das comparações de tonalidades e glaze das amostras encontrou-se que as múltiplas queimas, acima de nove vezes, não afetaram perceptivelmente a tonalidade das porcelanas e a aplicação de um tipo de porcelana a vários tipos de ligas, preciosas ou não preciosas, sob condições padrão, não melhora a tonalidade da porcelana ou - auto glaze depois de múltiplas queimas.

O'Brien et al. (1991), relataram que a cor final de coroas de porcelana depende da acurácia da combinação com a cor original da dentição feita pelo dentista e de variáveis introduzidas durante o processamento. A possível origem 
de variáveis no processamento incluem a espessura e cor do opaco; espessura, cor e transluscência das camadas de porcelanas de corpo e de esmalte; temperatura de queima e número de queimas. Estas variáveis de procedimento podem levar a um erro na tonalidade. A proposta deste estudo foi de quantificar em unidades do CIE Lab a variação total da cor $(\Delta E)$ quando o mesmo grupo foi queimado, entre diferentes grupos e quando levou-se em consideração as múltiplas queimas. Três lotes de seis tons e quatro marcas comerciais de porcelana foram usados, sendo elas Ceramco II, Jelenko, Vita VMK-68 e Will Ceram nas cores A2, A3, A3.5, B2, C2 e D4. O espectrofotômetro Color Eye foi utilizado para as medidas de cor que foram expressas na terminologia CIE Lab. A diferença de cor resultante das múltiplas queimas foi calculada como a diferença entre as médias de cor depois de seis queimas e as médias depois de três queimas. As mudanças na cor devido às múltiplas queimas foram então agrupadas de acordo com a marca comercial e tonalidade antes da análise estatística. A diferença na cor baseada na terceira queima como o padrão de comparação com a sexta foi de 1.00. Quando agrupadas por marca comercial, Vita e Ceramco mostraram a menor mudança de cor depois de seis queimas do que a Jelenko e Will-Ceram. Não houve diferença estatisticamente significante quando as amostras foram agrupadas por cor em um nível de confiança de $95 \%$. No geral, as diferenças na cor foram menores do que o esperado. 


\subsection{INFLUÊNCIA DA INFRA-ESTRUTURA METÁLICA NA ESTABILIDADE DE COR DAS CERÂMICAS ODONTOLÓGICAS}

Barghi e Richardson (1978), desenvolveram um trabalho onde foram confeccionadas 72 amostras com as ligas metálicas preciosas Ceramco R, SMG-2, Bak-On e Will-Ceram, sendo 18 amostras para cada liga. Após a confecção, os discos de liga metálica foram avaliados com um microscópio eletrônico de varredura antes e depois do tratamento de superfície. Receberam a aplicação da porcelana Ceramco e foram divididos em nove grupos de 8 amostras, sendo que nestas oito havia duas para cada liga. A porcelana recebeu glaze por nove vezes para a comparação das tonalidades. A avaliação visual das tonalidades foi realizada por seis observadores. Após isto, as amostras foram submetidas ao tratamento de superfície com pedras abrasivas e novamente avaliadas no microscópio eletrônico de varredura. Como resultados, encontraram que os quatro tipos de metais preciosos tiveram aspecto semelhante após a fundição $e$ tratamento de superfície, previamente a aplicação da porcelana; a porcelana aderida ao metal não teve sua tonalidade influenciada pelo tipo de metal precioso usado; e a tonalidade da porcelana aderida ao metal permaneceu estável depois de seis glazeamentos, e mudou suavemente depois de nove queimas.

Jacobs et al. 1987, realizaram um estudo com a finalidade de investigar visual e espectrofotometricamente as mudanças produzidas pelo tipo de liga metálica, espessura da porcelana e cor da porcelana no matiz, valor e croma de 
restaurações metalocerâmicas. Utilizaram três tipos de ligas, Jelenko "O" (ouroplatina-paládio), Unibond (níquel-cromo) e Option (alto teor de paládio), que foram testadas com a porcelana VMK-68 nas cores B1, A3 e C4. As espessuras das camadas de porcelana foram de 0,5, 1 e 1,5 mm para cada liga e cor empregadas. Foram confeccionadas 81 amostras, 27 para cada tipo de liga. A análise espectrofotométrica da cor foi realizada pelo espectrofotômetro General Eletric, os dados obtidos foram expressos na terminologia CIE Lab e convertidos às coordenadas do Sistema de Munsell. A análise visual foi realizada por quinze observadores, na qual as amostras foram divididas em dois grupos, um grupo de amostras da mesma liga e cor, mas diferentes espessuras; e o outro grupo com diferentes ligas. Concluíram que o tipo de liga usada produziu mínimas variações no matiz da porcelana nas avaliações visual e espectrofotométrica quando as cores B1 e C4 foram usadas. Entretanto, quando a cor A3 foi usada diferenças significativas no matiz foram notadas espectrofotometricamente entre as ligas de níquel-cromo e de alto teor de paládio, em comparação com a liga de ouro-platina-paládio. Nenhuma diferença significativa foi notada no croma ou valor. Visualmente, as amostras de níquel-cromo foram consideradas com significativas diferenças na cor na comparação com as outras ligas quando a cor A3 foi usada. Diferenças visuais e espectrofotométricas existiram com as diferentes espessuras de porcelana dentinária. As cores $A 3$ e $C 4$ foram mais afetadas do que a cor B1. Com as cores A3 e C4, diferenças entre as espessuras 
de $0,5,1$ e $1,5 \mathrm{~mm}$ da porcelana dentinária foram prontamente distinguidas. Pequena diferença foi percebida entre as três espessuras na cor B1 quando avaliada visual e espectrofotométricamente. Pareceu que quando a cor do opaco se aproximou mais da cor da porcelana, como no caso da cor B1, a cor pretendida foi alcançada com uma menor espessura de porcelana.

O'Neal et al. 1987, relataram que a habilidade das restaurações metalocerâmicas em imitar a cor dos dentes naturais é controlada por uma série de fatores. Um destes inclui as características de superfície do substrato. Este estudo investigou os efeitos da rugosidade de superfície e condicionadores no matiz, valor e croma de coroas de porcelana. Dois substratos metálicos diferentes, uma liga preciosa (Artisan) e uma liga metálica não preciosa (Biobond $C \&$ B), foram utilizados neste estudo. A porcelana Ceramco na cor 69 foi aplicada a estas ligas. As características da cor foram avaliadas através de um aparelho de medida de cor tridimensional, de um espectrofotômetro e pelo método visual após a aplicação do opaco e novamente após a aplicação da segunda camada de porcelana de corpo. Concluíram que para a espessura de porcelana usada neste estudo a maior variação de cor, que foi instrumentalmente notada, não teve importância clínica. $O$ acabamento de superfície afetou a coloração da restauração de forma suave, sendo que a mudança mais pronunciada foi notada para o matiz e croma, que são as dimensões da cor menos sensíveis aos observadores humanos. Os observadores notaram diferença de cor para as 
amostras não-preciosas em comparação com as amostras de liga áurea, o que indicou que a cor das restaurações pode ser afetada pela liga usada. $O$ efeito notado pelos observadores se deve provavelmente a uma diminuição no croma das amostras não-preciosas em comparação com a liga áurea. As ligas não-preciosas sempre têm croma diminuído quando mensuradas pelo Chromascan e espectrofotômetro. As mudanças de cor observadas apenas com a camada de opaco podem se tornar clinicamente significantes se a camada de porcelana de corpo for muito fina, como no caso do terço gengival de coroas metalocerâmicas e em áreas onde uma redução adequada do dente não pode ser realizada. A cor 69 usada neste estudo, que é mais acinzentada, apresentou alterações na cor, porém, estas mudanças notadas poderiam ter sido maiores se cores mais claras como a 59 ou 62 tivessem sido usadas. Os observadores humanos detectaram variações na comparação visual das amostras e estas diferenças foram relatadas como pequenas e sem significado clínico.

Crispin et al. 1991, testaram cinco das ligas mais comuns para a confecção de restaurações metalocerâmicas. Dez discos foram confeccionados com cada uma das seguintes ligas: Williams Y-1 (Hi - Au), Galaxy ( $\mathrm{Au}-\mathrm{Pd})$, Rexillium ( $\mathrm{Ni}$ Cr), Williams W-1 (Pd - Ag), e Option $(H i-P d)$. Cada disco recebeu três camadas do opaco Vita VMK - 68 paint-on 88 na cor A1. Após isto, cinco dos dez discos receberam a aplicação da porcelana de corpo Vita VMK - 68 na cor A1. As primeiras duas aplicações da porcelana de corpo foram queimadas sob vácuo. 0 
ciclo final de glazeamento foi realizado sem vácuo. Os outros cinco discos de cada grupo permaneceram apenas com as camadas de opaco, porém foram submetidos aos mesmos ciclos de queima que as amostras que receberam a porcelana. A análise colorimétrica das amostras foi realizada com o instrumento Minolta CR 100 Chroma Meter após a aplicação da terceira camada de opaco e depois do ciclo final de glazeamento. Todas as mensurações foram registradas em coordenadas do CIE Lab. Como resultados do estudo obtiveram que a estabilidade de cor da porcelana aplicada às ligas metálicas altamente nobres foi excelente. As ligas de paládio - prata e níquel - cromo tiveram como resultado uma significativa mudança de cor apenas na porcelana de corpo. A maior mudança de cor foi encontrada com a liga paládio - prata, a qual resultou em uma alta saturação no amarelo - verde. A liga níquel - cromo também produziu mudança de cor, sem dúvida não tão severa, resultando em uma porcelana com reduzido valor ou luminosidade.

Hammad e Stein (1991), realizaram este estudo com a finalidade de avaliar os efeitos dos múltiplos ciclos de queima, do tipo de liga metálica e marca da porcelana na cor de restaurações metalocerâmicas. Foram utilizadas as ligas metálicas Olympia e Talladium e as porcelanas Ceramco II e Vita VMK 68. As amostras possuíam $1 \mathrm{~mm}$ de espessura e tiveram a análise de sua cor realizada pelo colorímetro Minolta Chroma Meter, os dados foram expressos na terminologia CIE Lab e convertidos para a notação de Munsell. Concluíram que 
houve significativo aumento no matiz e diminuição no valor quando a temperatura de queima foi aumentada; não houve mudança significativa no croma quando a temperatura de queima foi aumentada para todas as combinações de liga $e$ porcelana testadas. Não houve significativa mudança no matiz, valor e croma das amostras quando o número de ciclos de queima foi aumentado. A porcelana Ceramco II mostrou significativo aumento no matiz em comparação com a porcelana Vita em todas as temperaturas de queima. Vita apresentou valor mais alto e croma significativamente mais alto e que a Ceramco II com ambas as ligas testadas. Os efeitos da mudança do tipo de liga no matiz, valor e croma variaram com a marca da porcelana usada em uma dada temperatura.

Stavridakis et al. (2000), avaliaram o efeito de diferentes ligas com alto teor de paládio na cor resultante do opaco. Foram analisadas três ligas de (PdCu-Ga) - Spartan Plus, Liberty e Freedom Plus; quatro ligas de (Pd-Ga) - Legacy, IS 85, Protocol, Legacy XT; e a liga de (Pd-Ag) - Super Star. A liga de (Au-Pd) Olympia serviu como controle. Foram confeccionadas 3 amostras para cada uma das ligas. O opaco Vita Omega na cor B1 foi aplicado nas amostras com uma espessura final de 0,1 mm. Depois de dois ciclos de queima do opaco, a cor foi mensurada com um colorímetro e os dados expressos na terminologia CIE Lab. As diferenças de cor $(\Delta E)$ foram determinadas entre o grupo controle e cada amostra do grupo experimental. Como resultados encontraram que as três ligas de $(\mathrm{Pd}-\mathrm{Cu}-\mathrm{Ga})$ apresentaram valores de $\Delta E$ significativamente grandes $(p<0,01)$ 
quando comparados com os cinco grupos experimentais remanescentes. As direções das significativas mudanças de cor foram de semelhante distribuição através dos eixos $L^{\star}, a^{\star} e b^{\star}$, e todos os valores de $\Delta L, \Delta a, \Delta b$ foram negativos. Concluíram que este trabalho sugere que uma camada de opaco com 0,1 $\mathrm{mm}$ de espessura nas ligas de ( $\mathrm{Pd}-\mathrm{Cu}-\mathrm{Ga})$ estudadas, não reproduziram de maneira confiável a cor da porcelana.

Stavridakis et al. (2004), realizaram um estudo in vitro com a finalidade de avaliar os efeitos de diferentes ligas com alto teor de paládio na cor resultante da porcelana dental, assim como no opaco, depois de simular os ciclos de queima da dentina e glaze. Foram avaliadas três ligas de (Pd-Cu-Ga) - Spartan Plus, Liberty e Freedom Plus; e cinco ligas de (Pd-Ga) - Legacy, IS 85, Protocol, Legacy XT e Jelenko $n^{\circ}$ 1. A liga de (Pd-Ag) - Super Star, foi incluída para ser comparada com as ligas de alto teor de paládio, a liga de (Au-Pd) - Olympia, serviu como controle. Seis amostras de cada liga foram confeccionadas e sobre elas foi aplicado o opaco Vita Omega na cor B1, com espessura de 0,1 mm. Após dois ciclos de queima do opaco as amostras foram divididas em dois grupos. 0 primeiro grupo recebeu a aplicação de 0,9 mm de porcelana dentinária na cor B1. O outro grupo de amostras ficou apenas com a camada de opaco, porém foi submetido aos mesmos ciclos de queima da porcelana dentinária e glaze que o outro grupo. Como resultados, após a aplicação da porcelana dentinária, as três ligas de (Pd-Cu-Ga) mostraram diferença estatisticamente significante quando 
comparadas com o grupo controle $(p<0,05)$. Depois do ciclo de glaze, as três ligas de $(\mathrm{Pd}-\mathrm{Cu}-\mathrm{Ga})$ e a liga de (Pd-Ag) exibiram diferença estatisticamente significante no $\Delta E$ quando comparadas com o grupo controle. Após a simulação dos ciclos de queima de dentina, as amostras que possuíam apenas a camada de opaco, exibiram os valores de $\Delta E$ com diferença estatisticamente significante quando comparadas com o grupo controle. As diferenças de cor entre as amostras das três ligas de (Pd-Cu-Ga), apenas com a camada de opaco, e o grupo controle aumentaram mais após a simulação do ciclo de glaze. As diferenças de cor observadas entre as ligas de $(P d-G a)$ e o grupo controle não foram estatisticamente significativas em qualquer dos pontos analisados. Assim concluíram que as ligas de (Pd-Cu-Ga) apenas com a camada de opaco, depois da simulação dos ciclos de queima da porcelana dentinária e glaze, exibiram diferenças de cor clinicamente inaceitáveis. A aplicação de porcelana dentinária às ligas de $(\mathrm{Pd}-\mathrm{Cu}-\mathrm{Ga})$ resultou em diferenças de cor clinicamente aceitáveis. $A$ aplicação da porcelana dentinária às ligas de ( $\mathrm{Pd}-\mathrm{Ag})$, após o ciclo de queima do glaze, resultou em diferenças de cor clinicamente aceitáveis (aproximadamente 2,8 a 3,7 unidades de $\Delta E$ ). As amostras da liga de ( $\mathrm{Pd}-\mathrm{Ag}$ ) apenas com as camadas de opaco não exibiram diferenças de cor significantes em comparação com o grupo controle, ao passo que diferenças de cor significantes, no grupo controle, depois da aplicação da porcelana dentinária e ciclos de queima do glaze continuaram clinicamente aceitáveis. 


\subsection{ENVELHECIMENTO ARTIFICIAL ACELERADO}

A investigação da estabilidade de cor das cerâmicas odontológicas através do processo de envelhecimento artificial acelerado, que simula os efeitos do tempo de utilização do material, não têm sido explorados na literatura de pesquisa odontológica. Existem poucos trabalhos abordando este assunto relacionado com as cerâmicas.

Razzoog et al. (1994), investigaram a estabilidade de cor das porcelanas Ceramco e Procera depois de serem submetidas a 900 horas de envelhecimento artificial acelerado. Vinte placas de titânio serviram de substrato onde as amostras da porcelana Procera nas cores A3, A3.5, C3 e D3 foram queimadas, cinco em cada cor. Vinte placas da liga para metalocerâmica Olympia foram confeccionadas para receber a porcelana Ceramco nas mesmas cores e forma que a anterior. As leituras de CIE Lab foram realizadas com o Minolta Chroma Metter II antes e depois da exposição a 900 horas de envelhecimento artificial acelerado. Depois do envelhecimento, a diferença de cor entre a condição anterior e posterior foi calculada. Foi observada diferença significativa entre as porcelanas nas cores A3, C3 e D3 depois de 900 horas de envelhecimento. A cor A3.5 não apresentou esta diferença. Para transformar a quantidade de mudança de $\operatorname{cor}(\Delta E)$ com significado clínico, os dados foram transformados para a National Bureau of Standards units (unidades NBS), na qual a quantidade de unidades NBS representa a condição clínica encontrada para a quantidade de 
variação da cor, conforme se segue: $0-0.5$ traço / esboço; $0.5-1.5$ pequena; 1.5 - 3.0 visível; 3.0 - 6.0 apreciável; 6.0 - 12.0 muito; 12.0 - demais. Para ambas as porcelanas, indiferentemente à cor usada, a maior quantidade de mudança de cor ocorreu nas primeiras 100 horas de envelhecimento e a porcelana Procera teve estatisticamente uma maior mudança de cor do que a porcelana Ceramco em três das quatro cores testadas. Ambas as porcelanas, em todas as cores, mostraram leve mudança de cor depois de 900 horas de envelhecimento e de fato exibiram o mesmo nível de mudança de cor depois das primeiras 100 horas. A comparação das diferentes porcelanas em unidades NBS, indiferentemente à cor, indicou que 900 horas de exposição ao Weather-O-Meter não levaram a uma mudança de cor clinicamente visível.

Heydecke et al. (2001), confeccionaram 15 discos de óxido de alumínio (Procera), estes foram divididos em 3 grupos, cada um com 5 discos. Um grupo recebeu a porcelana All Ceram na cor Vita A1, outro na cor Vita B4, e o último grupo permaneceu inacabado servindo como controle. As amostras dos dois primeiros grupos receberam auto glazeamento a $880^{\circ} \mathrm{C}$. Os discos foram unidos a substratos de compósito, que simularam dentes com descoloração. A cor das amostras foi medida com o colorímetro Minolta Chroma Meter II. Após, todos os espécimes foram submetidos a 300 horas de envelhecimento artificial acelerado, através da exposição à luz ultravioleta e spray de água no Weather-O-Meter. A cor foi novamente medida e os dados foram estatisticamente avaliados. 
Encontraram que as diferenças de cor entre os três grupos não foram estatisticamente significativas. A avaliação das diferenças de cor nos grupos separadamente revelou uma mudança significativamente alta na coordenada $b^{*}$ (azul - amarelo). Uma mudança significativa também foi observada na coordenada $a^{*}$ (vermelho - verde) e a diferença total de cor $(\Delta E=12,47)$ foi em função da forte mudança na direção do amarelo, como indicado pela coordenada $b^{\star}$. Uma mudança na luminosidade $L^{\star}$ foi observada nas amostras de porcelana nas cores A1 e B4. Entretanto, o nível de significância clínica $(\Delta E=3)$ não foi atingido em nenhum dos grupos. Em todos os três grupos, um aumento estatisticamente significativo no valor de $a^{\star}$ foi observado, relativo ao decréscimo no componente verde das amostras. As mudanças observadas na coordenada $b^{\star}$, entre os grupos, foram inconsistentes e nenhuma atingiu um nivel de significância. De forma geral, um aumento na luminosidade e decréscimo no croma foi observado. $O$ resultado total da diferença de cor $(\Delta E)$ nos três grupos de teste, discos, $A 1$ e B4, não foi clinicamente significativa, com uma exceção. No grupo da porcelana de cor B4, a mudança na luminosidade e no eixo verde - vermelho contribuiu para um $\Delta E$ de 3,34 unidades.

Ertan et al. (2005), desenvolveram um estudo com o propósito de estimar a estabilidade de cor de cerâmicas de baixa fusão ao longo do tempo, utilizando o processo de envelhecimento artificial acelerado. Foram utilizadas quatro marcas comerciais de cerâmica, sendo elas Vita Omega 900, Vita Titankeramik, Ceramco 
e Ceramco II, nas cores A3, B3 e C3. Confeccionaram um total de cento e vinte corpos-de-prova, dez amostras de cada cor para cada tipo de cerâmica. As amostras foram queimadas de acordo com as instruções dos fabricantes. As leituras de cor foram realizadas com o espectrofotômetro Shimadzu UV-2100 antes e após 100 horas de envelhecimento no Weather-O-Meter. Os resultados foram expressos na terminologia CIE Lab. A cerâmica Ceramco Finesse teve uma mudança de cor perceptível ao olho humano $(\Delta E>1)$. A mudança de cor das cerâmicas Ceramco II e Vita Omega 900 foram significativamente menores do que da Vita Titankeramik e Ceramco Finesse. Quando as tonalidades das cerâmicas foram comparadas, a C3 teve a maior mudança de cor em comparação com a $A 3$ e B3 e que foi detectável pelo o olho humano $(\Delta E>1)$. 
PROPOSIÇÃO 


\section{PROPOSIÇÃO}

O presente estudo teve como objetivos avaliar in vitro a estabilidade de cor de restaurações metalocerâmicas e livres de metal (metal-free) submetidas a dois, três e quatro ciclos de queima após envelhecimento artificial acelerado. 
MATERIAL E MÉTODOS 


\section{MATERIAL E MÉTODOS}

\subsection{MATERIAL}

Para a realização deste trabalho utilizou-se a cerâmica de corpo e incisal, ambas na cor A3, o líquido Medium e o opaco em pasta da marca comercial IPS $d$ SIGN (Ivoclar/Vivadent, Schaan, Liechtenstein - Figura 03). Para a obtenção das infra-estruturas metálicas dos corpos-de-prova metalocerâmicos foi utilizada a liga metálica Verabond II (Aaba Dent Inc, Cordelia, Ca, USA).

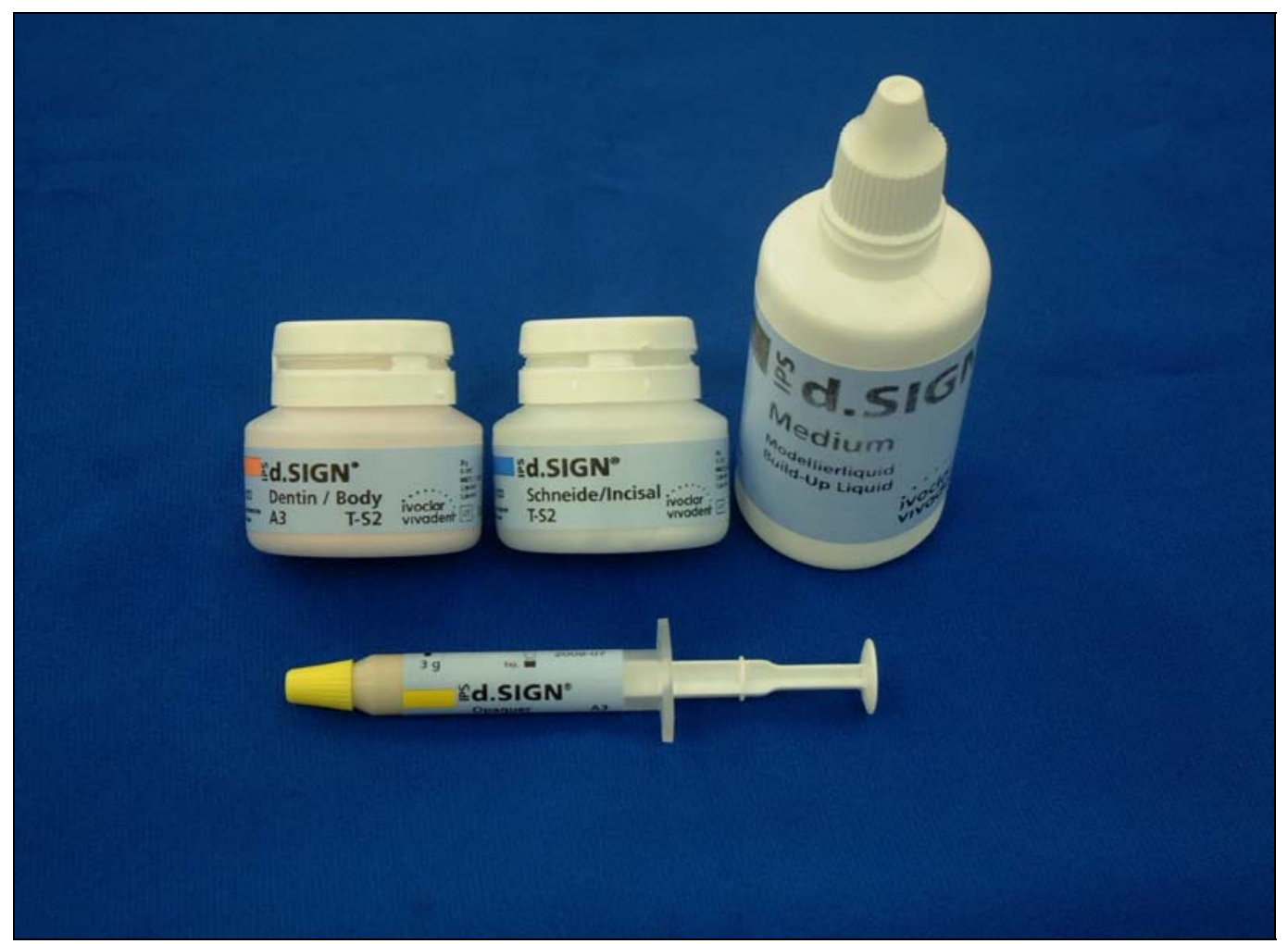

Figura 03 - Cerâmica IPS d-SIGN de corpo, incisal, líquido e opaco 


\subsection{MÉTODO}

\subsubsection{Confecção da matriz}

Para a obtenção dos corpos-de-prova confeccionou-se uma matriz em aço inoxidável com o interior perfeitamente liso e diâmetro interno de $15 \mathrm{~mm}$. A matriz era formada por uma porção externa e outra interna em forma de êmbolo, sendo que as duas partes se encaixavam (Figura 04). Acompanhando a matriz havia quatro espaçadores, dois deles com $1 \mathrm{~mm}$ de espessura, um com $2 \mathrm{~mm} e$ outro com $3 \mathrm{~mm}$, que eram encaixados no êmbolo entre as porções interna $e$ externa da matriz, de forma que a parte externa ficava mais alta que a interna proporcionando a espessura necessária do corpo-de-prova (Figura 07).
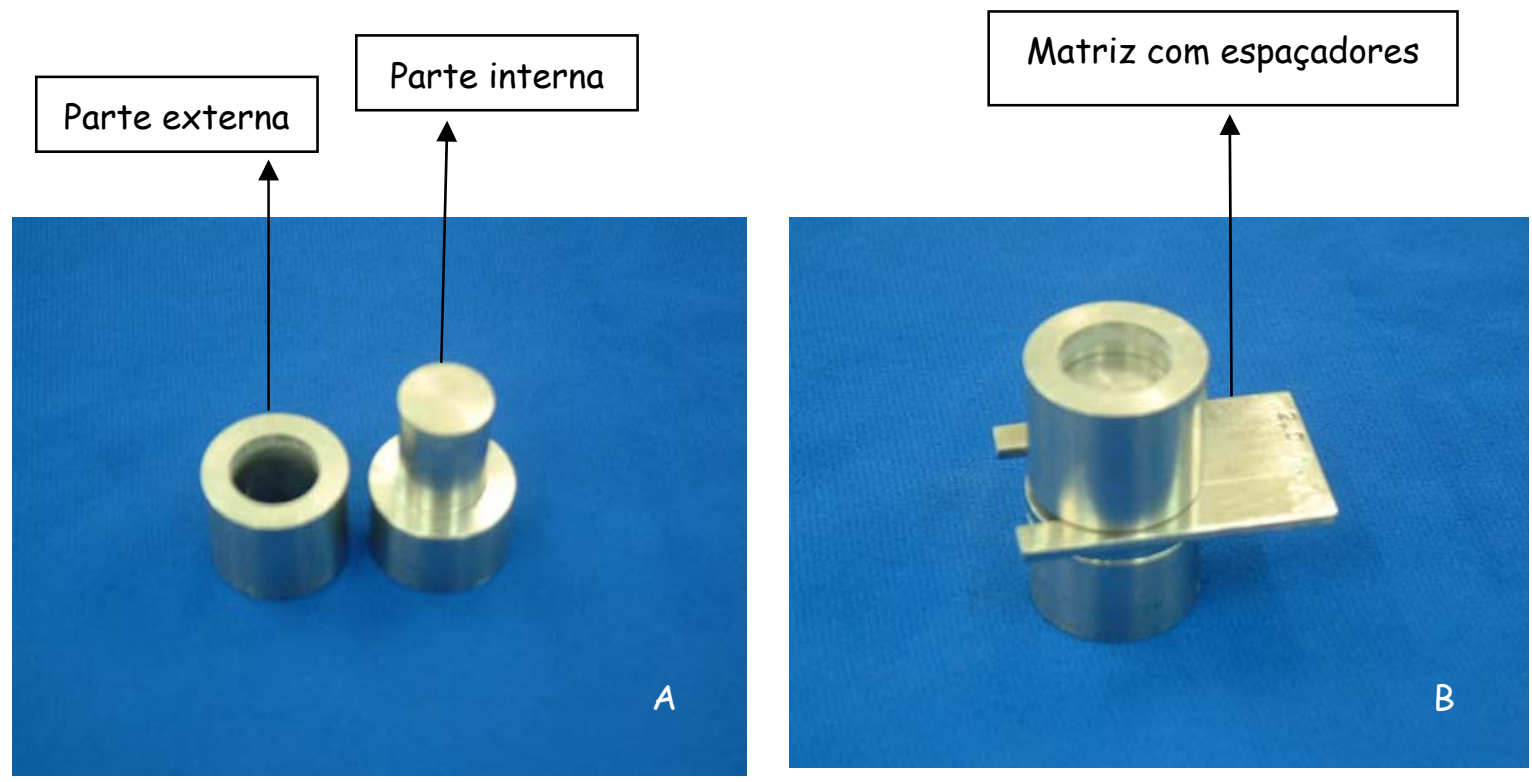

Figura 04 - A) Componentes da matriz metálica; B) Matriz metálica com espaçadores 


\subsection{2 - Confecção dos corpos-de-prova livres de metal}

Para a confecção dos corpos-de-prova livres de metal a cerâmica foi inserida diretamente na matriz, respeitando a espessura determinada pelo espaçador utilizado. Para a formação das camadas utilizavam-se os espaçadores relativos à espessura da camada, ou seja, para elaborar camadas de $5 \mathrm{~mm}$ utilizava-se os espaçadores de 2 e $3 \mathrm{~mm}$. Para camadas de $2 \mathrm{~mm}$, somente 0 espaçador de $2 \mathrm{~mm}$ era utilizado. A seqüência da confecção e queima das camadas pode ser vista na Tabela 01 e Figuras 05 a 07. Após a inserção de cada camada de cerâmica foi realizada a remoção do excesso de líquido através da colocação de papel absorvente sobre o material exercendo leve pressão manual. Em seguida, os corpos-de-prova eram levados ao forno para cocção (Figura 08) no programa 05 (Tabela 02).

A camada de cerâmica incisal com $1 \mathrm{~mm}$ de espessura foi inserida na matriz sobre a cerâmica de corpo (Tabela 02 / Figuras 09 e 10) e após sua inserção foi queimada no programa 06 (Tabela 01). Após a realização dos passos acima descritos as amostras apresentaram-se com formato semelhante à Figura 11. 


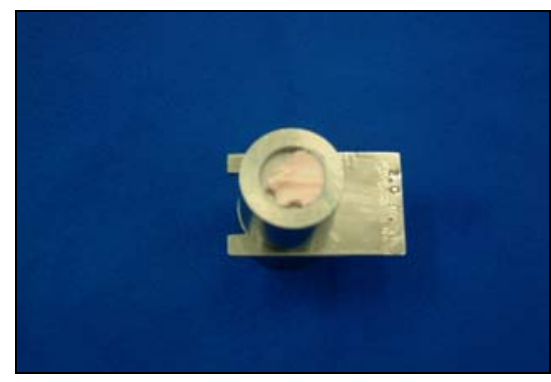

Figura 05 - Aplicação da primeira camada de cerâmica de corpo

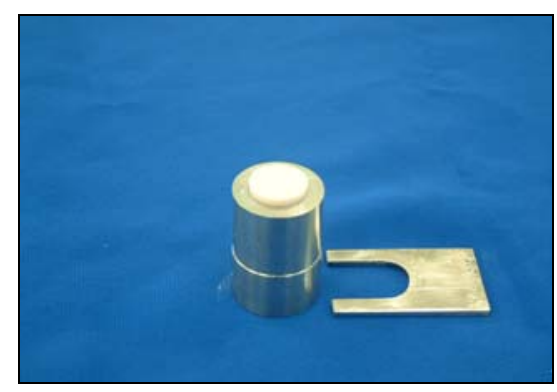

Figura 07 - Após a remoção do espaçador, 0 corpo-de-prova estava pronto para a cocção

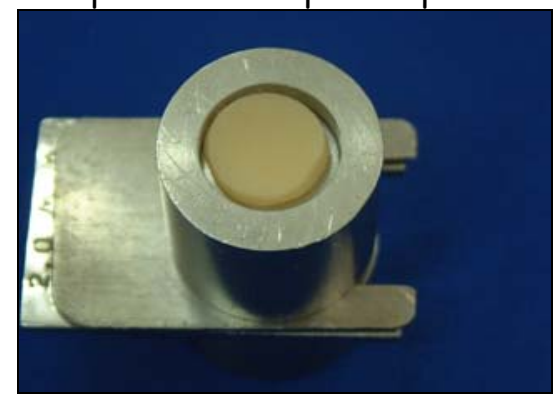

Figura 09 - Após a queima da cerâmica de corpo, o corpo-de-prova era levado novamente à matriz para receber a cerâmica incisal

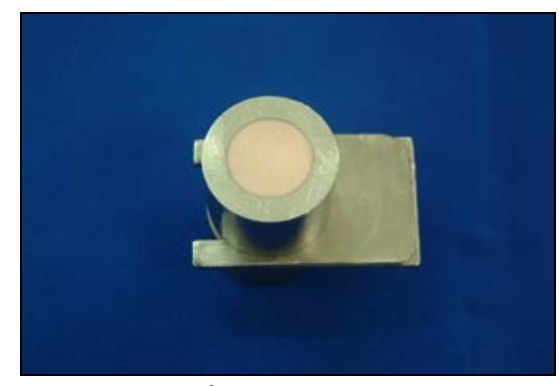

Figura 06 - A cerâmica de corpo era colocada na matriz até completar o espaço deixado pela colocação do espaçador no eixo da matriz

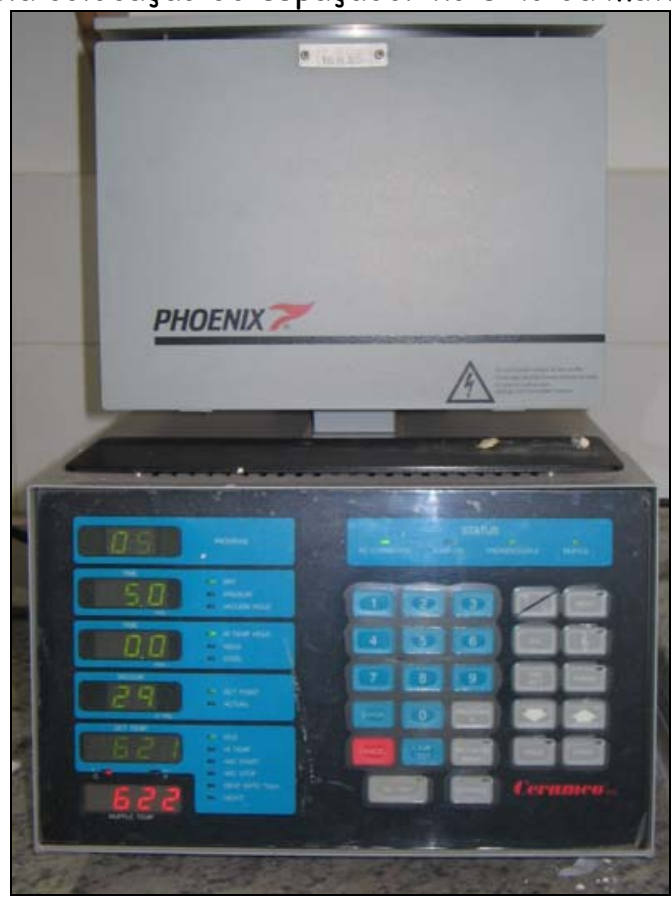

Figura 08 - Forno Phoenix (Ceramco, Burlington, USA)

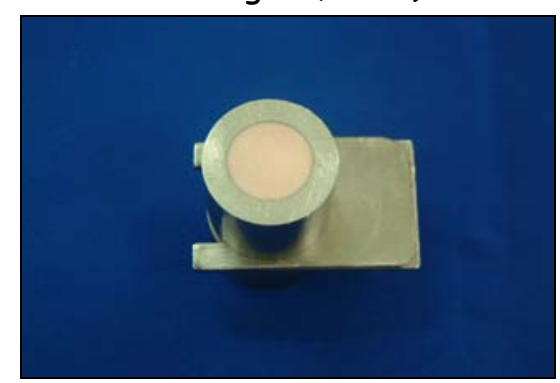

Figura 10 - Inserção da camada de cerâmica de incisal 
Tabela 01 - Sequência para confecção dos corpos-de-prova

\begin{tabular}{ccc} 
Número de queimas & \multicolumn{2}{c}{ Sequência das camadas } \\
2 & $5 \mathrm{Corpo}$ & Incisal \\
3 & $2 \mathrm{~mm}$ & \\
4 & $2 \mathrm{~mm}+3 \mathrm{~mm}$ & $1 \mathrm{~mm}$ \\
\hline
\end{tabular}

Tabela 02 - Programas para queima no forno

\begin{tabular}{cccc}
\hline PROGRAMAÇÃO & $\begin{array}{c}\text { TEMPERATURA } \\
\text { INICIAL }\end{array}$ & $\begin{array}{c}\text { TEMPERATURA } \\
\text { FINAL }\end{array}$ & $\begin{array}{c}\text { POLEGADAS DE } \\
\text { VÁCUO }\end{array}$ \\
\hline 01 & $649^{\circ} \mathrm{C}$ & $974^{\circ} \mathrm{C}$ & 29 \\
02 & $649^{\circ} \mathrm{C}$ & $954^{\circ} \mathrm{C}$ & 29 \\
05 & $621^{\circ} \mathrm{C}$ & $918^{\circ} \mathrm{C}$ & 29 \\
06 & $621^{\circ} \mathrm{C}$ & $913^{\circ} \mathrm{C}$ & 29 \\
08 & $621^{\circ} \mathrm{C}$ & $918^{\circ} \mathrm{C}$ & $\times$ \\
\hline
\end{tabular}

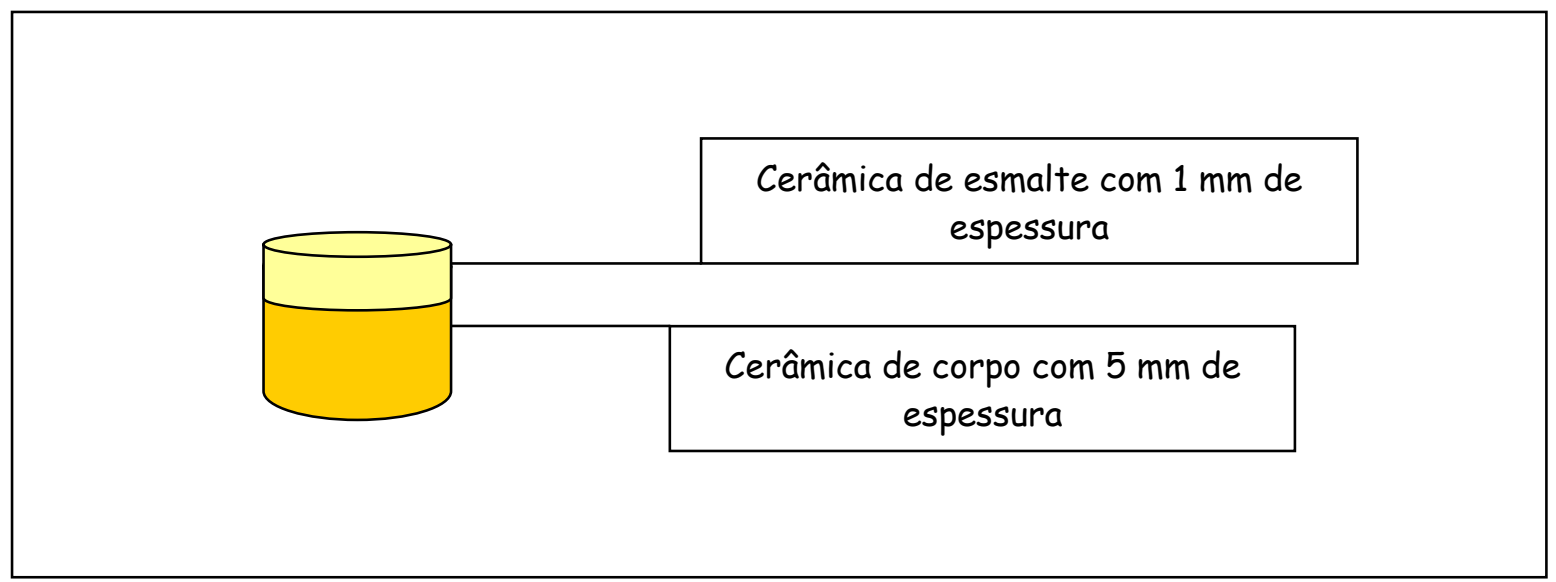

Figura 11 - Esquema ilustrativo das camadas dos corpos-de-prova livres de metal

4.2.3. Confecção dos discos metálicos correspondentes às infra-

\section{estruturas}

A obtenção das infra-estruturas metálicas das restaurações metalocerâmicas se deu de acordo com a técnica da cera perdida (ANUSAVICE, 2005). Dessa maneira, sobre a matriz metálica previamente isolada com pequena quantidade de vaselina e ajustada em $1 \mathrm{~mm}$ com o auxílio do espaçador, verteu-se 
cera fundida com um conta-gotas até o completo preenchimento da matriz. Aguardou-se o completo endurecimento da cera, retirou-se o excesso com uma espátula quente e removeu-se da matriz a partir da remoção do espaçador. Após a obtenção do padrão de cera, este foi incluído em revestimento fosfatado Thermocast (Polidental, Cotia, SP, Brasil) e procedeu-se a fundição segundo descrito em Anusavice (2005).

Depois de fundidos, os discos receberam acabamento com jato de óxido de alumínio. Para promover a união metal/cerâmica, os discos foram inicialmente desgastados com ponta de óxido de alumínio e, em seguida, novamente jateados com óxido de alumínio e submetidos à limpeza por imersão em álcool isopropílico em ultra-som por 10 minutos.

\subsubsection{Confecção dos corpos-de-prova metalocerâmicos}

Após a limpeza da estrutura metálica, estas foram secas com papel absorvente e receberam a primeira camada de opaco que foi aplicada com pincel em movimentos sempre na mesma direção (Figura 12A), e levados ao forno (Figura 08) para a queima no programa 01 (Tabela 02). A segunda e terceira camadas de opaco foram aplicadas da mesma forma que a primeira e levadas ao forno para a queima no programa 02 (Tabela 02). Dessa forma, os discos ficavam prontos para receber a cerâmica (Figura 12B). 

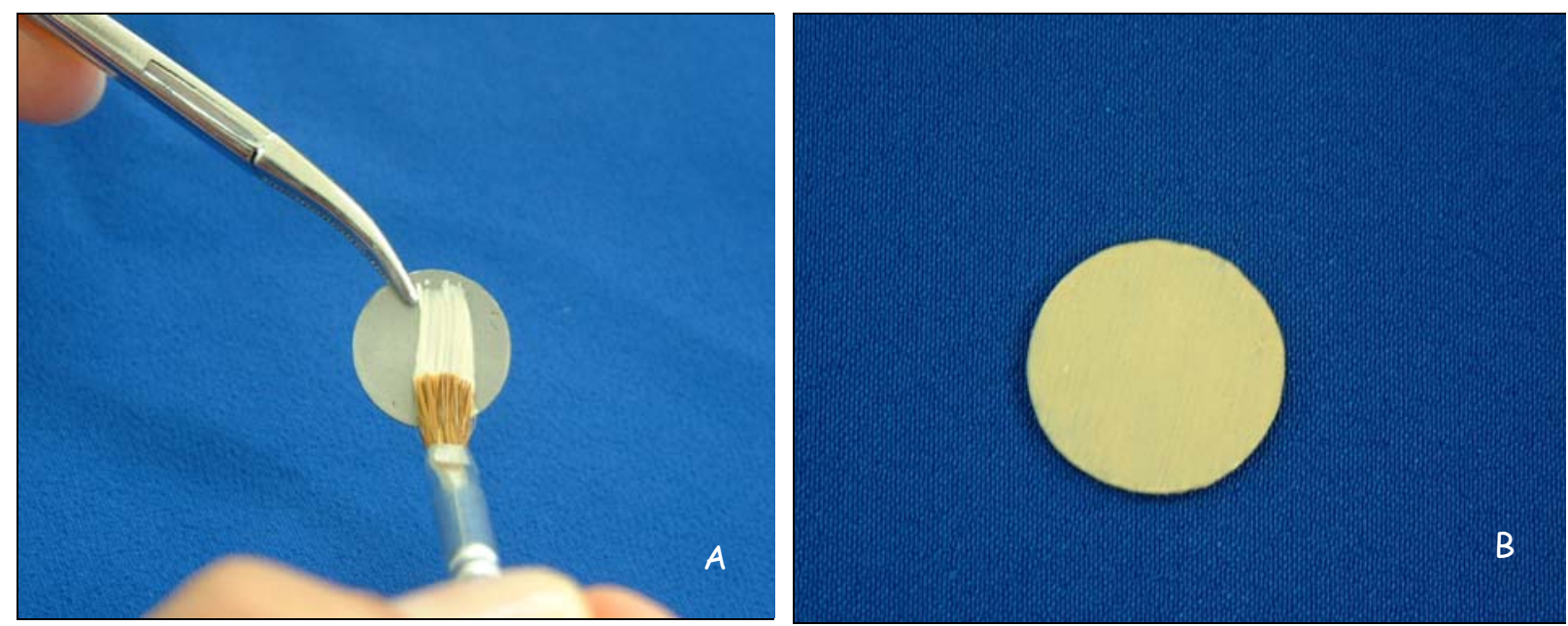

Figura 12 - A) Aplicação da primeira camada de opaco; B) infra-estrutura metálica pronta para receber a cerâmica

As infra-estruturas de $1 \mathrm{~mm}$ de espessura foram colocadas no interior da matriz metálica e a primeira camada de cerâmica de corpo na cor $A 3$ foi inserida à semelhança do processo utilizado para a confecção dos corpos-de-prova livres de metal. Para compensar a espessura da infra-estrutura metálica, o espaçador de $1 \mathrm{~mm}$ foi utilizado desde o início, antes da confecção da primeira camada. A sequiência da confecção e queima das camadas pode ser vista na Tabela 01. Após a condensação da cerâmica, os corpos-de-prova eram levados ao forno para cocção (Figura 08) no programa 05 (Tabela 02).

A camada de cerâmica incisal com $1 \mathrm{~mm}$ de espessura foi inserida na matriz sobre a cerâmica de corpo (Tabela 01) e após sua inserção foi queimada no programa 06 (Tabela 02). Após a realização dos passos acima descritos as amostras apresentaram-se com formato semelhante à Figura 13. 


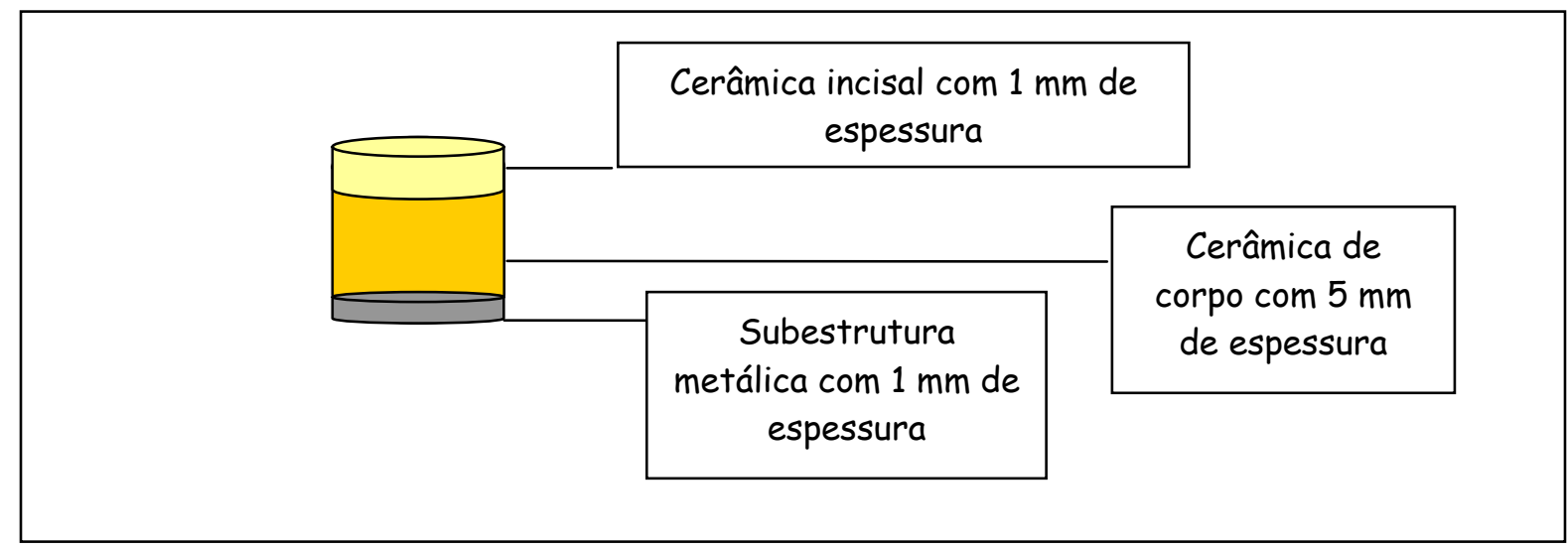

Figura 13 - Esquema ilustrativo das camadas dos corpos-de-prova metalocerâmicos

\subsubsection{Acabamento dos corpos-de-prova}

Todas as amostras, após a sua confecção, receberam o acabamento da superfície em politriz manual para aplainamento da sua superfície, através de lixas nas granulações 100, 320, 600, 800 e 1000.

\subsubsection{Glazeamento dos corpos-de-prova}

Após a obtenção de superfícies planas e lisas, todas as sessenta amostras receberam o glazeamento, sendo novamente levadas ao forno no programa 08 (Tabela 02). Realizado o glazeamento as amostras estavam prontas para os testes (Figuras 14 e 15). 


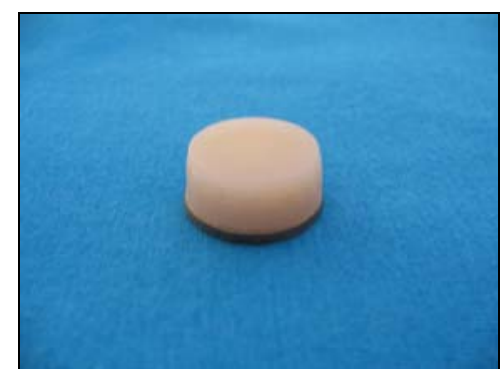

Figura 14 - Corpo-de-prova metalocerâmico

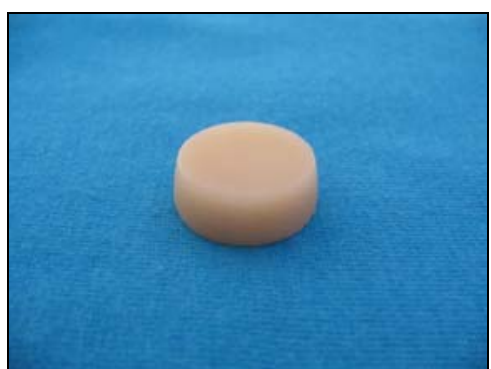

Figura 15 - Corpo-de-prova livre de metal

\subsubsection{Análise espectrofotométrica da cor dos corpos-de-prova antes e após o processo de envelhecimento artificial acelerado}

Após a confecção, as amostras foram submetidas à leitura da cor através do Espectrofotômetro PCB 6807 BYK GARDNER (Geretsried, Alemanha) que pode ser visto na Figura 16. As amostras receberam em sua base uma marcação que possibilitou a padronização das leituras de cor, através do seu posicionamento sempre no mesmo local na abertura do aparelho (Figura 17), sendo colocado sobre elas o bloco de fundo padrão branco (Standard For $45^{\circ}, 0^{\circ}$, Reflectance and Color Gardner Laboratory Inc. Bethesda, Maryland 20014) Figura 18.

Uma vez acionado, pela pressão sobre o conjunto, o equipamento emite luzes de componentes LED - 30 lâmpadas LED, com 10 cores diferentes, dispostas de forma circular, que acendem e incidem o feixe de luz em $45^{\circ}$ com a superfície do material. Esse feixe é refletido em $0^{\circ}$ de volta para 0 aparelho, e assim este capta e registra os valores de $L^{*}, a^{\star}$ e $b^{\star}$ de cada amostra, tornando possível a medição quantitativa da cor do material. 
Após as leituras de cor as amostras foram submetidas ao Processo de Envelhecimento Artificial Acelerado. Após o envelhecimento, os corpos-de-prova foram novamente submetidos à análise de cor para a verificação da mudança total de $\operatorname{cor}(\Delta E)$, que foi calculado pela fórmula:

$$
\Delta E=\sqrt{\left(\Delta L^{2}\right)+\left(\Delta a^{2}\right)+\left(\Delta b^{2}\right)}
$$

Onde: $\Delta L=$ variação de $L^{*}$ (antes e após o envelhecimento)

$$
\begin{aligned}
& \Delta a=\text { variação de } a^{*} \\
& \Delta b=\text { variação de } b^{*}
\end{aligned}
$$

Quando $\Delta E$ resultasse em valores $\geq 3,3$ a modificação de cor seria considerada clinicamente inaceitável (RUYTER et al., 1987; MUTLU-SAGESEN et al., 2001; STOBER et al., 2001).

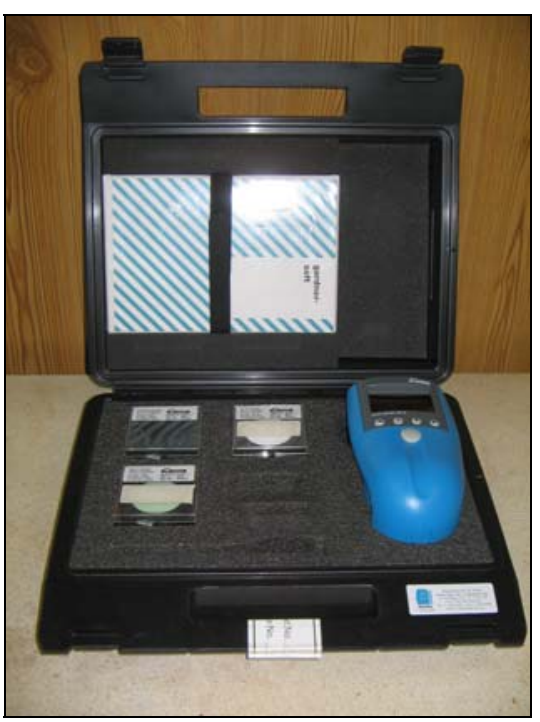

Figura 16 - Espectrofotômetro PCB 6807 BYK GARDNER 


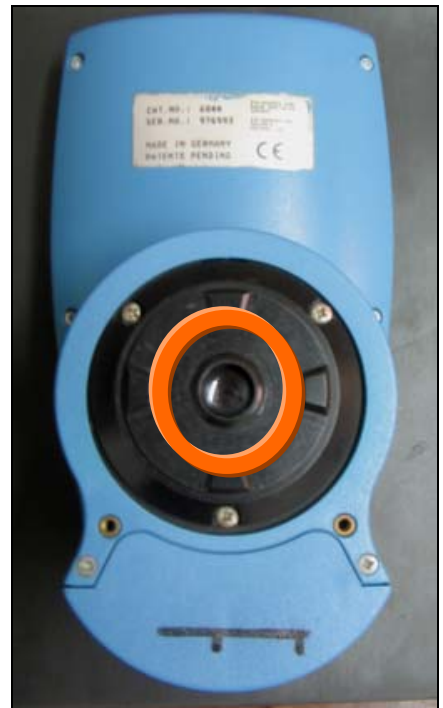

Figura 17 - Em destaque a abertura do equipamento para a realização das leituras de cor

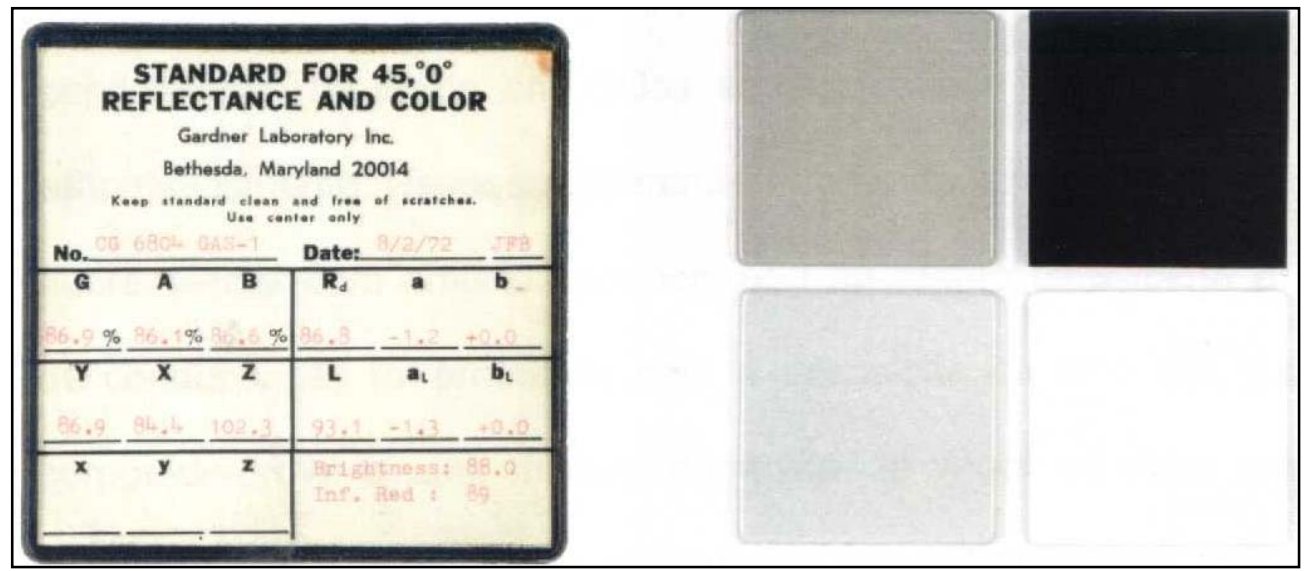

Figura 18 - Blocos de fundo padrão utilizados para a leitura de cor.

\subsubsection{Processo de envelhecimento artificial acelerado}

O envelhecimento foi realizado no aparelho Sistema Acelerado de Envelhecimento para Não-Metálicos - UV-B/Condensação (Comexim Matérias Primas Indústria e comércio LTDA - São Paulo - SP - Brasil) - Figura 19. O sistema de envelhecimento artificial acelerado simula as forças da natureza predizendo a durabilidade relativa dos materiais expostos às intempéries. A chuva e a neblina são simuladas pelo processo de condensação de água destilada, 
saturada de oxigênio auto gerado pelo sistema. Os efeitos da luz do sol, onde apenas $1 \%$ da radiação provoca degradação, são simulados por uma rede de 8 fontes de luz UV-B com radiação concentrada em $280 / 320 \mathrm{~nm}$ como na natureza. A temperatura de exposição é automaticamente controlada de acordo com os programas estabelecidos para ciclos UV/condensação.

Os corpos-de-prova foram aderidos às placas fixadoras do aparelho utilizando-se silicone especificamente indicado para tal, e levados à câmara de condensação frente à fonte de luz, numa distância de $50 \mathrm{~mm}$ desta (Figura 20). O programa de funcionamento fixado foi de 4 horas de exposição ao UV-B a $50^{\circ}$ $C$ e 4 horas de condensação a $50^{\circ} \mathrm{C}$, o tempo máximo de envelhecimento foi de 384 horas.

Após o término do processo de envelhecimento artificial acelerado os corpos-de-prova foram novamente submetidos à análise de cor para a verificação da mudança total de cor $(\Delta E)$.

Em seguida os resultados foram submetidos à análise estatística segundo a verificação de normalidade. 


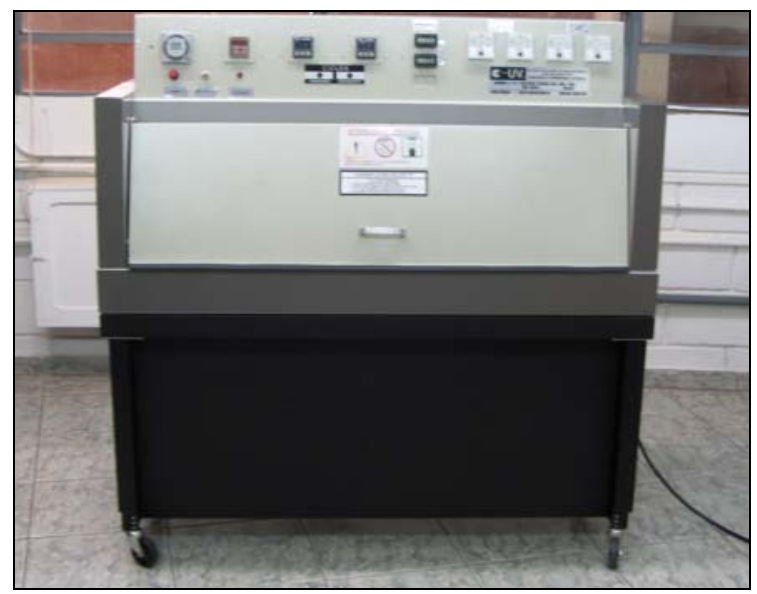

Figura 19 - Sistema Acelerado de Envelhecimento para não-metálicos C-UV

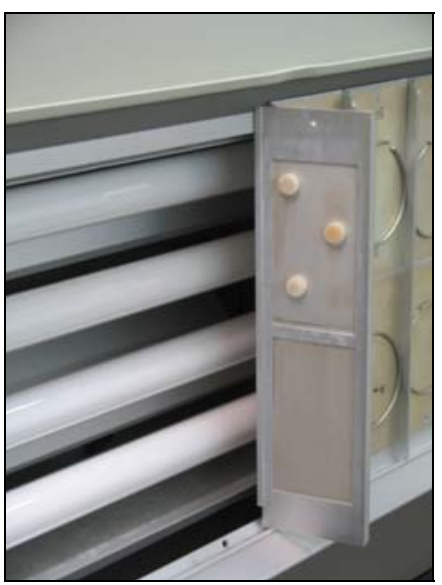

Figura 20 - Amostras aderidas à placa fixadora em frente à fonte de luz 
RESULTADOS 


\section{RESULTADOS}

Os resultados obtidos nas leituras de cor das amostras metalocerâmicas submetidas a duas, três e quatro queimas, antes e após o envelhecimento acelerado juntamente com os valores da variação total das coordenadas $L^{*}, a^{*} e$ $b^{\star}$ e variação total de cor das amostras estão descritos nas tabelas 03 a 05 respectivamente.

Tabela 03 - Resultados das leituras de cor para as amostras metalocerâmicas confeccionadas em duas

\begin{tabular}{ccccccccccc}
\hline & \multicolumn{3}{c}{ ANTES } & \multicolumn{4}{c}{ APÓS } & \multicolumn{4}{c}{ VARIAÇÃO } \\
\hline & $L^{*}$ & $a^{\star}$ & $b^{\star}$ & $L^{*}$ & $a^{\star}$ & $b^{*}$ & $\Delta L^{*}$ & $\Delta a^{*}$ & $\Delta b^{*}$ & $\Delta E$ \\
\hline 1 & 61,90 & 1,56 & 10,23 & 61,58 & 1,5 & 10,29 & $-0,31$ & $-0,05$ & 0,05 & 0,31 \\
2 & 60,70 & 1,54 & 10,54 & 60,39 & 1,4 & 10,6 & $-0,3$ & $-0,14$ & 0,06 & 0,33 \\
3 & 62,64 & 1,63 & 9,95 & 62,24 & 1,43 & 10,09 & $-0,4$ & $-0,2$ & 0,14 & 0,46 \\
4 & 60,83 & 1,68 & 10,44 & 60,47 & 1,48 & 10,42 & $-0,36$ & $-0,19$ & $-0,02$ & 0,4 \\
5 & 61,93 & 1,66 & 10,48 & 61,62 & 1,43 & 10,42 & $-0,31$ & $-0,23$ & $-0,05$ & 0,38 \\
6 & 61,19 & 1,46 & 9,92 & 60,72 & 1,25 & 9,91 & $-0,46$ & $-0,21$ & 0 & 0,5 \\
7 & 61,09 & 1,65 & 10,52 & 60,66 & 1,46 & 10,57 & $-0,42$ & $-0,19$ & 0,04 & 0,46 \\
8 & 62,13 & 1,38 & 9,90 & 61,71 & 1,16 & 9,98 & $-0,42$ & $-0,21$ & 0,08 & 0,47 \\
9 & 61,53 & 1,73 & 10,89 & 61,12 & 1,56 & 10,87 & $-0,41$ & $-0,16$ & $-0,01$ & 0,44 \\
10 & 62,72 & 1,57 & 10,81 & 62,25 & 1,37 & 10,89 & $-0,46$ & $-0,19$ & 0,07 & 0,5
\end{tabular}

Tabela 04 - Resultados das leituras de cor para as amostras metalocerâmicas confeccionadas em três queimas

\begin{tabular}{|c|c|c|c|c|c|c|c|c|c|c|}
\hline & \multicolumn{3}{|c|}{ ANTES } & \multicolumn{3}{|c|}{ APÓS } & \multicolumn{4}{|c|}{ VARIAÇÃO } \\
\hline & $L^{*}$ & $a^{\star}$ & $b^{\star}$ & $L^{*}$ & $a^{\star}$ & $b^{*}$ & $\Delta L^{*}$ & $\Delta a^{\star}$ & $\Delta b^{*}$ & $\Delta E$ \\
\hline 1 & 62,79 & 1,78 & 11,02 & 62,24 & 1,58 & 11,09 & $-0,54$ & $-0,2$ & 0,06 & 0,57 \\
\hline 2 & 62,89 & 1,49 & 9,87 & 62,38 & 1,3 & 9,84 & $-0,5$ & $-0,19$ & $-0,02$ & 0,53 \\
\hline 3 & 64,84 & 1,43 & 9,93 & 64,25 & 1,23 & 10,02 & $-0,59$ & $-0,2$ & 0,08 & 0,62 \\
\hline 4 & 63,11 & 1,51 & 10,04 & 62,56 & 1,31 & 9,94 & $-0,55$ & $-0,19$ & $-0,1$ & 0,59 \\
\hline 5 & 61,96 & 1,66 & 10,80 & 61,38 & 1,42 & 11 & $-0,57$ & $-0,24$ & 0,19 & 0,64 \\
\hline 6 & 62,84 & 1,57 & 9,70 & 62,29 & 1,37 & 9,77 & $-0,55$ & $-0,2$ & 0,07 & 0,58 \\
\hline 7 & 61,78 & 1,82 & 10,98 & 61,31 & 1,61 & 11,08 & $-0,47$ & $-0,21$ & 0,09 & 0,52 \\
\hline 8 & 63,94 & 1,57 & 10,86 & 63,48 & 1,47 & 10,88 & $-0,46$ & $-0,1$ & 0,01 & 0,47 \\
\hline 9 & 63,35 & 1,80 & 10,93 & 62,77 & 1,69 & 10,93 & $-0,57$ & $-0,11$ & 0 & 0,58 \\
\hline 10 & 63,07 & 1,57 & 10,73 & 62,52 & 1,39 & 10,76 & $-0,55$ & $-0,17$ & 0,03 & 0,57 \\
\hline
\end{tabular}


Tabela 05 - Resultados das leituras de cor para as amostras metalocerâmicas confeccionadas em quatro queimas

\begin{tabular}{ccccccccccc}
\hline & \multicolumn{3}{c}{ ANTES } & \multicolumn{3}{c}{ APÓS } & \multicolumn{4}{c}{ VARIAÇÃO } \\
\hline & $L^{*}$ & $a^{*}$ & $b^{*}$ & $L^{*}$ & $a^{*}$ & $b^{*}$ & $\Delta L^{*}$ & $\Delta a^{*}$ & $\Delta b^{*}$ & $\Delta E$ \\
\hline 1 & 62,85 & 1,34 & 10,16 & 62,31 & 1,17 & 10,07 & $-0,53$ & $-0,16$ & $-0,08$ & 0,55 \\
2 & 63,79 & 1,13 & 9,51 & 63,25 & 1,02 & 9,45 & $-0,54$ & $-0,11$ & $-0,05$ & 0,55 \\
3 & 61,74 & 1,69 & 10,95 & 61,4 & 1,48 & 10,99 & $-0,34$ & $-0,2$ & 0,04 & 0,39 \\
4 & 61,52 & 1,54 & 10,43 & 60,89 & 1,42 & 10,32 & $-0,62$ & $-0,12$ & $-0,11$ & 0,64 \\
5 & 61,97 & 1,44 & 10,30 & 61,44 & 1,25 & 10,23 & $-0,52$ & $-0,19$ & $-0,07$ & 0,55 \\
6 & 62,07 & 1,53 & 10,87 & 61,54 & 1,37 & 10,96 & $-0,53$ & $-0,16$ & 0,08 & 0,55 \\
7 & 61,77 & 1,44 & 10,05 & 61,26 & 1,27 & 10,07 & $-0,5$ & $-0,16$ & 0,01 & 0,52 \\
8 & 61,67 & 1,54 & 11,05 & 61,13 & 1,38 & 10,94 & $-0,54$ & $-0,16$ & $-0,1$ & 0,57 \\
9 & 61,52 & 1,64 & 10,80 & 61,13 & 1,49 & 10,67 & $-0,39$ & $-0,14$ & $-0,13$ & 0,43 \\
10 & 61,57 & 1,75 & 11,31 & 61,33 & 1,58 & 11,27 & $-0,23$ & $-0,16$ & $-0,04$ & 0,28 \\
\hline
\end{tabular}

Os resultados obtidos nas leituras de cor das amostras livres de metal submetidas a duas, três e quatro queimas, antes e após o envelhecimento acelerado juntamente com os valores da variação total das coordenadas $L^{*}, a^{*} e$ $b^{\star}$ e variação total de cor das amostras estão descritos nas tabelas 06 a 08 respectivamente.

Tabela 06 - Resultados das leituras de cor para as amostras livres de metal confeccionadas em duas queimas

\begin{tabular}{ccccccccccc}
\hline & \multicolumn{3}{c}{ ANTES } & \multicolumn{1}{c}{ APÓS } & \multicolumn{4}{c}{ VARIAÇÃO } \\
\hline & $L^{*}$ & $a^{\star}$ & $b^{*}$ & $L^{*}$ & $a^{*}$ & $b^{*}$ & $\Delta L^{*}$ & $\Delta a^{*}$ & $\Delta b^{*}$ & $\Delta E$ \\
\hline 1 & 64,94 & 1,94 & 11,46 & 64,58 & 1,82 & 11,46 & $-0,35$ & $-0,11$ & 0 & 0,36 \\
2 & 63,53 & 2,03 & 11,88 & 63,16 & 1,88 & 11,98 & $-0,36$ & $-0,15$ & 0,09 & 0,4 \\
3 & 67,36 & 2,11 & 11,25 & 67,16 & 1,99 & 11,33 & $-0,2$ & $-0,12$ & 0,08 & 0,24 \\
4 & 64,16 & 1,29 & 9,78 & 63,7 & 1,21 & 9,91 & $-0,46$ & $-0,08$ & 0,12 & 0,48 \\
5 & 66,30 & 1,55 & 9,66 & 66,08 & 1,45 & 9,9 & $-0,22$ & $-0,1$ & 0,23 & 0,33 \\
6 & 64,40 & 1,99 & 10,72 & 64,14 & 1,79 & 10,79 & $-0,25$ & $-0,19$ & 0,07 & 0,32 \\
7 & 64,23 & 2,22 & 12,12 & 63,89 & 2,14 & 12,23 & $-0,34$ & $-0,08$ & 0,1 & 0,36 \\
8 & 65,72 & 1,58 & 10,19 & 65,32 & 1,46 & 10,26 & $-0,39$ & $-0,11$ & 0,07 & 0,41 \\
9 & 64,51 & 1,81 & 10,69 & 64,1 & 1,73 & 10,89 & $-0,4$ & $-0,07$ & 0,19 & 0,44 \\
10 & 63,32 & 1,80 & 10,83 & 62,78 & 1,67 & 10,9 & $-0,54$ & $-0,12$ & 0,07 & 0,55 \\
\hline
\end{tabular}


Tabela 07 - Resultados das leituras de cor para as amostras livre de metal confeccionadas em três queimas

\begin{tabular}{ccccccccccc}
\hline & \multicolumn{3}{c}{ ANTES } & \multicolumn{3}{c}{ APÓS } & \multicolumn{4}{c}{ VARIAÇÃO } \\
\hline & $L^{*}$ & $a^{*}$ & $b^{*}$ & $L^{*}$ & $a^{*}$ & $b^{*}$ & $\Delta L^{*}$ & $\Delta a^{*}$ & $\Delta b^{*}$ & $\Delta E$ \\
\hline 1 & 62,63 & 2,19 & 12,15 & 62,34 & 2,04 & 12,18 & $-0,29$ & $-0,14$ & 0,02 & 0,32 \\
2 & 61,56 & 2,19 & 13,26 & 61,31 & 2,16 & 13,33 & $-0,24$ & $-0,03$ & 0,07 & 0,25 \\
3 & 64,22 & 1,82 & 11,18 & 63,92 & 1,76 & 11,31 & $-0,29$ & $-0,05$ & 0,12 & 0,31 \\
4 & 63,27 & 2,10 & 11,90 & 63,04 & 1,95 & 11,94 & $-0,23$ & $-0,14$ & 0,03 & 0,27 \\
5 & 62,37 & 2,41 & 13,22 & 62,07 & 2,3 & 13,19 & $-0,3$ & $-0,11$ & $-0,03$ & 0,32 \\
6 & 64,23 & 2,54 & 14,28 & 63,88 & 2,37 & 14,23 & $-0,34$ & $-0,17$ & $-0,05$ & 0,38 \\
7 & 61,58 & 2,22 & 12,74 & 61,23 & 2,08 & 12,72 & $-0,34$ & $-0,13$ & $-0,02$ & 0,36 \\
8 & 63,52 & 2,28 & 12,58 & 63,24 & 2,08 & 12,48 & $-0,27$ & $-0,19$ & $-0,1$ & 0,34 \\
9 & 61,78 & 2,06 & 12,43 & 61,49 & 1,96 & 12,44 & $-0,28$ & $-0,1$ & 0 & 0,29 \\
10 & 67,39 & 1,57 & 9,54 & 66,78 & 1,41 & 9,64 & $-0,61$ & $-0,15$ & 0,1 & 0,63 \\
\hline
\end{tabular}

Tabela 13 - Resultados das leituras de cor para as amostras livre de metal confeccionadas em quatro queimas

\begin{tabular}{ccccccccccc}
\hline & \multicolumn{3}{c}{ ANTES } & \multicolumn{4}{c}{ APÓS } & \multicolumn{4}{c}{ VARIAÇÃO } \\
\hline & $L^{*}$ & $a^{\star}$ & $b^{*}$ & $L^{*}$ & $a^{*}$ & $b^{*}$ & $\Delta L^{*}$ & $\Delta a^{*}$ & $\Delta b^{*}$ & $\Delta E$ \\
\hline 1 & 62,33 & 2,66 & 13,92 & 61,99 & 2,54 & 14,01 & $-0,34$ & $-0,11$ & 0,08 & 0,36 \\
2 & 64,46 & 2,72 & 15,93 & 64,06 & 2,6 & 16,04 & $-0,39$ & $-0,12$ & 0,1 & 0,42 \\
3 & 62,11 & 2,86 & 13,83 & 61,69 & 2,72 & 13,89 & $-0,41$ & $-0,13$ & 0,06 & 0,43 \\
4 & 61,69 & 2,60 & 12,75 & 61,57 & 2,44 & 12,79 & $-0,11$ & $-0,15$ & 0,04 & 0,19 \\
5 & 62,34 & 3,00 & 13,48 & 61,98 & 2,84 & 13,58 & $-0,36$ & $-0,15$ & 0,09 & 0,4 \\
6 & 63,57 & 2,67 & 13,83 & 63,07 & 2,46 & 13,81 & $-0,49$ & $-0,21$ & $-0,01$ & 0,53 \\
7 & 63,54 & 2,87 & 15,33 & 63,06 & 2,74 & 15,34 & $-0,47$ & $-0,13$ & 0 & 0,48 \\
8 & 62,16 & 2,34 & 12,19 & 61,8 & 2,2 & 12,13 & $-0,36$ & $-0,13$ & $-0,06$ & 0,38 \\
9 & 63,44 & 2,66 & 15,46 & 63,08 & 2,61 & 15,43 & $-0,36$ & $-0,04$ & $-0,02$ & 0,36 \\
10 & 62,21 & 2,64 & 12,88 & 61,63 & 2,42 & 12,92 & $-0,57$ & $-0,21$ & 0,03 & 0,6 \\
\hline
\end{tabular}

Todos os valores obtidos como resultados da comparação entre os grupos de duas, três e quatro queimas dentro das amostras metalocerâmicas e dentro do grupo das amostras livres de metal foram submetidos à análise estatística através da análise de variância e Teste de Tukey com grau de confiança de 95\%. Quando a comparação foi realizada entre as amostras metalocerâmicas e livres de metal os dados foram submetidos à análise estatística através do teste $\dagger$ de Student com nível de significância de 95\%. 
Inicialmente procedeu-se a comparação dos valores de $L^{\star} a^{\star} e b^{\star}$ antes envelhecimento acelerado para que fosse possível verificar se o número de queimas propiciava variação de cor, independente do envelhecimento da restauração. Dessa maneira, na Tabela 14 pode-se visualizar os valores das médias e dos respectivos desvios-padrão das coordenadas $L^{\star} a^{\star} b^{\star}$ das amostras metalocerâmicas e livres de metal antes do envelhecimento acelerado. Esses valores foram comparados estatisticamente através do teste † de Student. Os dados para as amostras metalocerâmicas podem ser vistos nas Tabelas 15 a 17 e para as amostras livres de metal nas Tabelas 18 a 20 para coordenadas $L^{*} a^{*} e$ $b^{\star}$ respectivamente.

Tabela 14 - Médias e desvios-padrão das medidas das coordenadas $L^{*} a^{\star} e$ b* antes do envelhecimento acelerado dos corpos-de-prova submetidos a 2, 3 e 4 ciclos de queimas

\begin{tabular}{llccc}
\hline & & 2 queimas & 3 queimas & 4 queimas \\
\hline \multirow{3}{*}{ Metalocerâmicas } & $L^{*}$ & $61,28(0,70)$ & $62,52(0,87)$ & $61,57(0,70)$ \\
& $a^{*}$ & $1,40(0,12)$ & $1,44(0,15)$ & $1,34(0,17)$ \\
& $b^{*}$ & $10,4(0,34)$ & $10,53(0,56)$ & $10,5(0,56)$ \\
\hline \multirow{3}{*}{ Livres de metal } & $L^{*}$ & $64,5(1,33)$ & $62,89(1,69)$ & $62,36(0,86)$ \\
& $a^{*}$ & $1,8(0,29)$ & $2,12(0,28)$ & $2,64(0,18)$ \\
& $b^{*}$ & $10,9(0,80)$ & $12,32(1,25)$ & $13,92(1,24)$ \\
\hline
\end{tabular}

Tabela 15 - Comparação da coordenada $L^{*}$ entre as amostras metalocerâmicas confeccionadas em duas, três e quatro queimas antes do envelhecimento acelerado pelo teste t de Student com nível de significância de $95 \%$

\begin{tabular}{cccc}
\hline & $M C 2$ & $M C 3$ & $M C 4$ \\
\hline$M C 2$ & & $p<0,01$ & $n s$ \\
$M C 3$ & $p<0,01$ & & $p<0,05$ \\
$M C 4$ & $n s$ & $p<0,05$ & \\
\hline
\end{tabular}

$n s=$ não significante $(p>0,05)$ 
Tabela 16 - Comparação da coordenada $a^{*}$ entre as amostras metalocerâmicas confeccionadas em duas, três e quatro queimas antes do envelhecimento acelerado pelo teste t de Student com nível de significância de $95 \%$

\begin{tabular}{cccc}
\hline & $M C 2$ & $M C 3$ & $M C 4$ \\
\hline$M C 2$ & & $n s$ & $n s$ \\
$M C 3$ & $n s$ & & $n s$ \\
$M C 4$ & $n s$ & $n s$ & \\
\hline \multicolumn{4}{r}{$n s=$ não significante (p>0,05) }
\end{tabular}

Tabela 17 - Comparação da coordenada $b^{*}$ entre as amostras metalocerâmicas confeccionadas em duas, três e quatro queimas antes do envelhecimento acelerado pelo teste t de Student com nível de significância de $95 \%$

\begin{tabular}{cccc}
\hline & $M C 2$ & $M C 3$ & $M C 4$ \\
\hline$M C 2$ & & $n s$ & $n s$ \\
$M C 3$ & $n s$ & & $n s$ \\
$M C 4$ & $n s$ & $n s$ & \\
\hline \multicolumn{4}{r}{$n s=$ não significante (p>0,05) }
\end{tabular}

Tabela 18 - Comparação da coordenada L* entre as amostras livres de metal confeccionadas em duas, três e quatro queimas antes do envelhecimento acelerado pelo teste t de Student com nível de significância de $95 \%$

\begin{tabular}{cccc}
\hline & MF 2 & MF 3 & MF 4 \\
\hline MF 2 & & $p<0,05$ & $p<0,01$ \\
MF 3 & $p<0,05$ & & $n s$ \\
MF 4 & $p<0,01$ & $n s$ & \\
\hline \multicolumn{4}{c}{$n s=$ não significante (p>0 05) }
\end{tabular}

Tabela 19 - Comparação da coordenada $a^{\star}$ entre as amostras livres de metal confeccionadas em duas, três e quatro queimas antes do envelhecimento acelerado pelo teste t de Student com nível de significância de $95 \%$

\begin{tabular}{|c|c|c|c|}
\hline & MF 2 & MF 3 & MF 4 \\
\hline MF 2 & & $p<0,05$ & $p<0,001$ \\
\hline MF 3 & $p<0,05$ & & $p<0,001$ \\
\hline MF 4 & $p<0,001$ & $p<0,001$ & \\
\hline
\end{tabular}

Tabela 20 - Comparação da coordenada $b^{\star}$ entre as amostras livres de metal confeccionadas em duas, três e quatro queimas antes do envelhecimento acelerado pelo teste t de Student com nível de significância de 95\%

\begin{tabular}{cccc}
\hline & $M F 2$ & $M F 3$ & $M F 4$ \\
\hline$M F 2$ & & $p<0,05$ & $p<0,001$ \\
$M F 3$ & $p<0,05$ & & $p<0,01$ \\
$M F 4$ & $p<0,001$ & $p<0,01$ \\
\hline \multicolumn{4}{c}{ ns = não significante ( $p>0,05)$}
\end{tabular}


Após a análise da interferência dos ciclos de queima sobre a variação de cor das restaurações estudadas, procedeu-se a verificação da interferência do envelhecimento artificial acelerado. Para isso, foram comparados os valores de $\Delta E$ das amostras. Esses valores foram comparados através da Análise de Variância - Tukey com nível de significância de 95\% (Tabela 21 - Gráfico 01)

Tabela 21 - Comparação das médias e desvio-padrão de $\triangle E$ (ANOVA - Tukey - 95\%)

\begin{tabular}{cccc}
\hline & 2 queimas & 3 queimas & 4 queimas \\
\hline Metalocerâmica & $0,42(0,07) a, A$ & $0,57(0,05) b, A$ & $0,50(0,10) a b, A$ \\
Livre de metal & $0,39(0,09) a, A$ & $0,35(0,11) a, B$ & $0,41(0,11) a, B$ \\
\hline
\end{tabular}

Letras diferentes, minúsculas na linha e maiúsculas na coluna, indicam significância estatística $(p<0,05)$

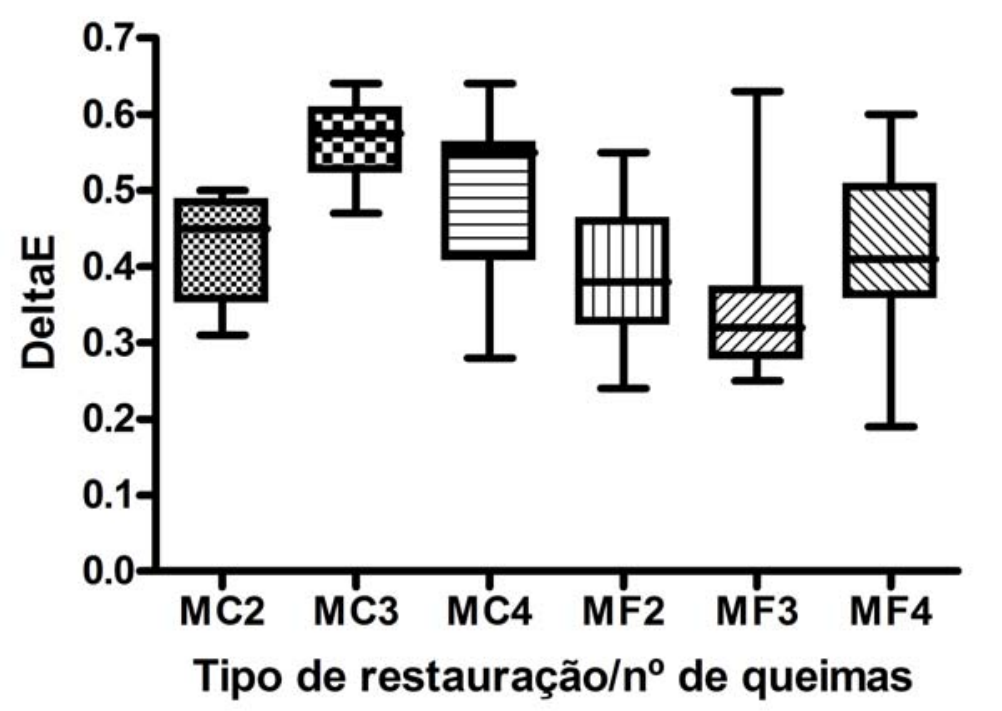

MC2 - metalocerâmica - duas queimas

MC3 - metalocerâmica - três queimas

MC4 - metalocerâmica - quatro queimas

MF2 - livres de metal - duas queimas

MF3 - livres de metal - três queimas

MF4 - livres de metal - quatro queimas
Gráfico 01 - Variação total da cor nas amostras metalocerâmicas e livres de metal após múltiplos ciclos de queima e envelhecimento acelerado

Comparou-se também a variação de cada coordenada $(\Delta L, \Delta a$ e $\Delta b)$ nas

diferentes amostras após o envelhecimento artificial acelerado. Para isso, as 
médias de variação das coordenadas foram submetidas à análise de variância -

Tukey - nível de significância de 95\% (Tabelas 22 a 24 - Gráficos 02 a 04)

Tabela 22 - Comparação das médias e desvio-padrão de $\Delta L$ (ANOVA - Tukey - 95\%)

\begin{tabular}{cccc}
\hline & 2 queimas & 3 queimas & 4 queimas \\
\hline Metalocerâmica & $-0,38(0,06) a, A$ & $-0,53(0,04) b, A$ & $-0,47(0,12) a b, A$ \\
Livre de metal & $-0,35(0,11) a, A$ & $-0,31(0,11) a, B$ & $-0,39(0,12) a, A$ \\
\hline
\end{tabular}

Letras diferentes, minúsculas na linha e maiúsculas na coluna, indicam significância estatística $(p<0,05)$

\section{DeltaL}

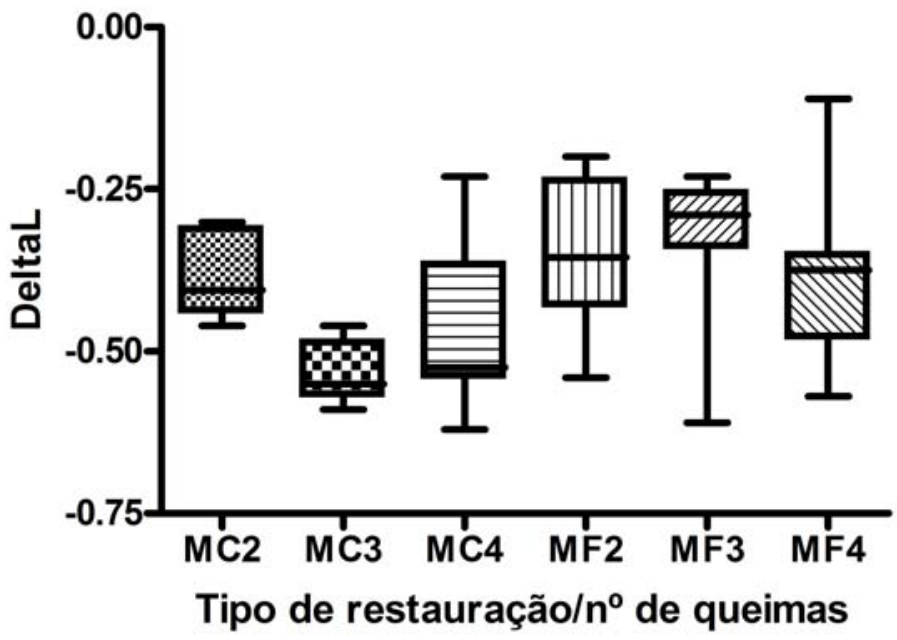

MC2 - metalocerâmica - duas queimas

MC3 - metalocerâmica - três queimas

MC4 - metalocerâmica - quatro queimas

MF2 - livres de metal - duas queimas

MF3 - livres de metal - três queimas

MF4 - livres de metal - quatro queimas

Gráfico 02 - Variação total da luminosidade nas amostras metalocerâmicas e livres de metal após múltiplos ciclos de queima e envelhecimento acelerado

Tabela 23 - Comparação das médias e desvio-padrão de $\triangle a$ (ANOVA - Tukey - 95\%)

\begin{tabular}{cccc}
\hline & 2 queimas & 3 queimas & 4 queimas \\
\hline Metalocerâmica & $-0,18(0,05) a, A$ & $-0,18(0,04) a, A$ & $-0,17(0,03) a, A$ \\
Livre de metal & $-0,11(0,03) a, B$ & $-0,12(0,05) a, B$ & $-0,14(0,05) a, A$ \\
\hline Letras diferentes, minúsculas na linha e maiúsculas na coluna, indicam significância estatística \\
$(p<0,05)$
\end{tabular}




\section{Delta a}

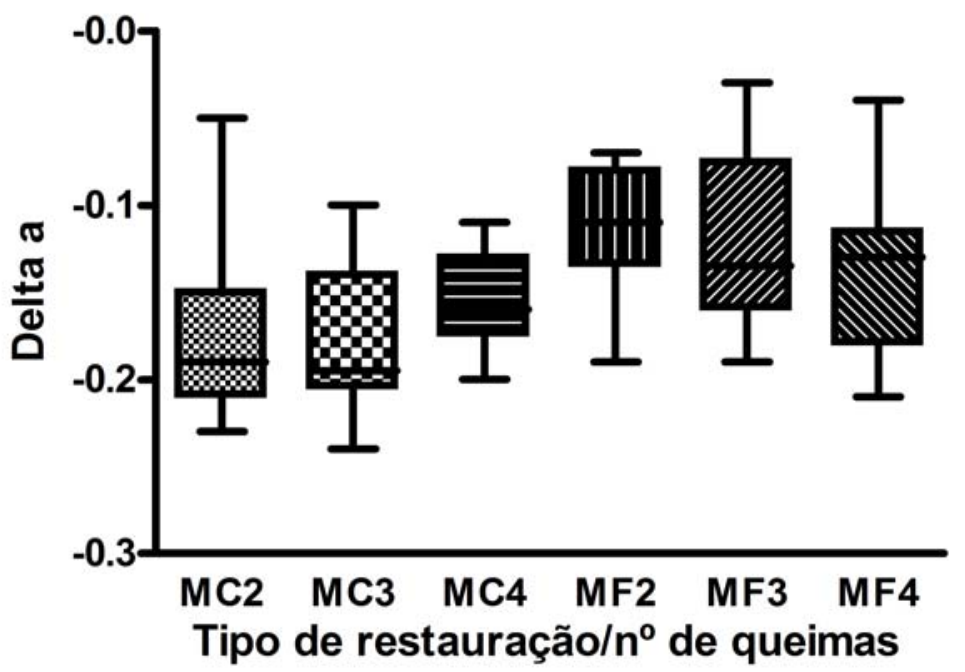

MC2 - metalocerâmica - duas queimas

MC3 - metalocerâmica - três queimas

MC4 - metalocerâmica - quatro queimas

MF2 - livres de metal - duas queimas

MF3 - livres de metal - três queimas

MF4 - livres de metal - quatro queimas

Gráfico 03 - Variação total da coordenada $a^{\star}$ nas amostras metalocerâmicas e livres de metal após múltiplos ciclos de queima e envelhecimento acelerado

Tabela 24 - Comparação das médias e desvio-padrão de $\triangle b$ (ANOVA - Tukey - 95\%)

\begin{tabular}{cccc}
\hline & 2 queimas & 3 queimas & 4 queimas \\
\hline Metalocerâmica & $0,04(0,06) a, A$ & $0,04(0,08) a, A$ & $-0,04(0,07) b, A$ \\
Livre de metal & $0,10(0,06) a, B$ & $0,01(0,07) a b, A$ & $0,03(0,05) b, B$ \\
\hline
\end{tabular}

Letras diferentes, minúsculas na linha e maiúsculas na coluna, indicam significância estatística $(p<0,05)$

Delta b

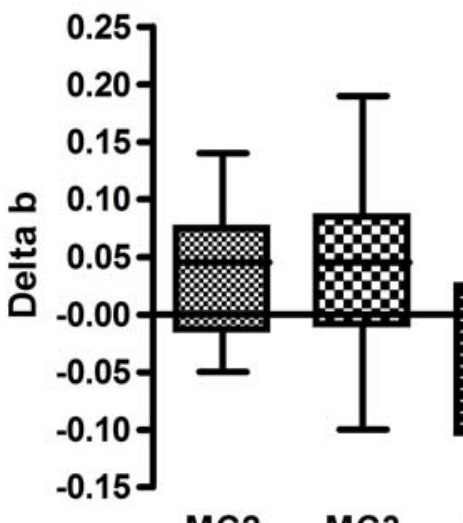

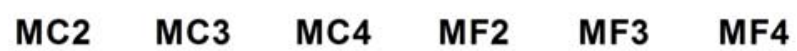

Tipo de restauração $/ n^{\circ}$ de queimas

Gráfico 04 - Variação total da coordenada b* nas amostras metalocerâmicas e livres de metal após múltiplos ciclos de queima e envelhecimento acelerado

MC2 - metalocerâmica - duas queimas MC3 - metalocerâmica - três queimas MC4 - metalocerâmica - quatro queimas MF2 - livres de metal - duas queimas MF3 - livres de metal - três queimas MF4 - livres de metal - quatro queimas 
DISCUSSÃO 


\section{DISCUSSÃO}

Em relação aos fatores relacionados com a fase laboratorial da construção de uma restauração cerâmica, o número de vezes que a cerâmica é levada ao forno para a cocção pode ser responsável pela diferença entre a cor pretendida e a cor alcançada na restauração final. Dependendo da magnitude desta diferença de cor, o tratamento restaurador pode ser considerado insatisfatório, o que determinaria a substituição da restauração.

Analisando-se os resultados, verificou-se que as amostras metalocerâmicas não apresentaram diferenças estatisticamente significantes nas coordenadas $L^{*}$, $a^{\star} e b^{\star}$ entre os grupos de duas e quatro queimas. As amostras livres de metal apresentaram diferenças estatisticamente significantes entre todos os grupos nas coordenadas $a^{\star}$ e $b^{*}$, e na coordenada $L^{*}$ esta diferença foi percebida no grupo confeccionado em duas queimas quando comparado com os grupos de três e quatro queimas. As amostras metalocerâmicas, quando comparadas com as amostras livres de metal, apresentaram valores menores nas coordenadas $L^{*}, a^{\star}$ $e b^{\star}$ em todos os grupos, porém foram diferenças muito pequenas.

Estas pequenas diferenças estatísticas podem ser explicadas devido à contração sofrida pela cerâmica no momento da cocção. Durante a elaboração das amostras, e também das restaurações na prática laboratorial, o pó da cerâmica deve ser misturado a um líquido para haver a condensação desse material. Quanto maior a quantidade desse líquido, maior é a contração da cerâmica após a 
coç̧ão (ANUSAVICE, 2005), mesmo com a remoção do excesso de líquido no momento da condensação.

Apesar de todo o cuidado ter sido tomado durante a condensação da cerâmica no momento da confecção das amostras, a camada de cerâmica de corpo pode ter sofrido grande contração, principalmente no caso em que foi submetida a 2 queimas. Dessa maneira, a camada de cerâmica incisal pode ter ficado mais espessa e com isso a amostra tornou-se mais clara. Caso isso tenha ocorrido ao contrário, ou seja, se a camada de cerâmica de corpo sofreu pequena contração, a camada de cerâmica incisal foi menos espessa e com isso a amostra ficou mais escura. Os resultados encontrados no presente estudo corroboram os de Jorgenson e Goodkind (1979). Segundo os autores, a espessura da camada de cerâmica tem influência direta na cor.

Outro fator que pode explicar as diferenças encontradas é a forma artesanal com que as amostras foram confeccionadas, $e$ por isto muitos artefatos de técnica podem ter sido incorporados no processo, pois não há como padronizá-lo.

Apesar da análise dos resultados ter identificado significância estatística, as variações foram pequenas, ou seja, muito abaixo de 3,3. Segundo Ruyter et al. (1987); Mutlu-Sagesen et al. (2001); Stober et al. (2001), essa variação para ser considerada clinicamente inaceitável, deve ser maior que 3,3. Além disso, para que ela seja percebida clinicamente, esse valor deve ser maior que 1,0 (MUTLU- 
SAGESEN et al., 2001; STOBER et al., 2001). Além do mais, as variações se apresentaram com baixos valores de desvios-padrão.

A inexistência de alteração de cor, encontrada neste estudo, em função do número de ciclos de queima a que a cerâmica é submetida tem respaldo em trabalhos de outros autores como Barghi e Goldberg (1977); Barghi e Richardson (1978); Jorgenson e Goodkind (1979); Barghi (1982); O'Brien et al. (1991).

O processo de envelhecimento artificial acelerado não proporcionou alterações de cor significativas, o que está de acordo com os estudos dos autores Razzoog et al. (1994); Heydecke et al. (2001); Ertan et al. (2005). Isso pode ser explicado devido à natureza mineral que esse material apresenta. Esse material não apresenta qualquer conteúdo orgânico, como a matriz orgânica das resinas compostas diretas ou indiretas. Dessa maneira, não há como o envelhecimento degradar qualquer componente do material, como acontece com os compósitos (REIS, 2003; ZANIN, 2005).

A infra-estrutura metálica pode exercer influência na alteração da cor da porcelana em restaurações metalocerâmicas. Esta influência está relacionada com diversos fatores como a espessura da camada de porcelana, com a cor do opaco utilizado e com o tipo de liga metálica empregada. A comparação das médias das coordenada $L^{*}, a^{\star} e b^{\star}$ dos grupos metalocerâmicos e livres de metal mostrou que as amostras de cerâmica pura apresentaram maior luminosidade e valores das coordenadas $a^{\star} e b^{\star}$ em todos os grupos após a confecção com os 
dois, três e quatro ciclos de queima, e se mantiveram maiores depois do envelhecimento acelerado. A menor luminosidade das amostras metalocerâmicas já era esperada em função da infra-estrutura metálica que interfere nas propriedades ópticas do material, diminuindo sua translucidez (CRAIG; POWERS, 2004). Concordando com o que foi encontrado neste estudo Crispin (1991), relatou que a liga de níquel-cromo proporcionou uma porcelana com menor luminosidade. Autores como Stavridakis et al. (2000 e 2004), relataram que o tipo de liga empregada tem influência direta na coloração. Hammad e Stein (1991), alegaram que a alteração de cor provocada pela liga metálica depende da marca da cerâmica e da temperatura de cocção, outros autores como Jacobs et al. (1987), afirmaram que a alteração de cor está relacionada com a cor da cerâmica, cor do opaco e o método de avaliação da cor. Outro fator que também tem influência na cor juntamente com o tipo de liga empregada é a espessura da camada de cerâmica conforme os autores Jacob set al. (1987) e O'Neal et al. (1987). Já o autor Barghi (1982), encontrou que as ligas metálicas tanto preciosas como não-preciosas não tiveram influência na cor da porcelana.

Apesar das diferenças de valores encontradas na comparação das amostras metalocerâmicas com as livres de metal, estas foram muito pequenas e não representaram diferenças visíveis ou com relevância clínica, podendo-se dizer que a estabilidade de cor do material, nas formas em que foi empregado, foi 
comparável. Este fato pode estar relacionado com a grande espessura de cerâmica (6 mm) utilizada neste estudo.

Esperava-se que as amostras metalocerâmicas apresentassem maiores valores de alteração de cor após envelhecimento artificial acelerado devido à interface metal/cerâmica. Acreditava-se que, como essa união se dá por meios químicos (CRAIG; POWERS, 2004), ela poderia ser degradada principalmente em função do processo de condensação. Porém, isso não ocorreu mostrando que essa união é muito eficiente (ALMILHATTI et al., 2003).

Outro fator que pode contribuir para a mínima alteração de cor desse material é o glaze. Esse passo laboratorial, responsável por dar um aspecto vítreo à restauração (CRAIG; POWERS, 2004; ANUSAVICE, 2005) também permite que, no momento do glaze, haja o escoamento do material cerâmico nas pequenas irregularidades superficiais. Isso permite que haja um "selamento" da restauração, impedindo que os fatores externos possam alterar a cor do material.

Porém, alguns fatores podem alterar essa camada de glaze, como agentes químicos, como os ácidos dos alimentos, e mesmo o ato da escovação e o flúor que - compõe. Dessa maneira, novos estudos são necessários para avaliar se esses outros fatores podem levar a alterações de cor das cerâmicas. 
CONCLUSÃO 


\section{CONCLUSÃO}

Os resultados obtidos com este estudo permitem as seguintes conclusões:

1. Os múltiplos ciclos de queima não modificaram de forma significativa a estabilidade de cor da cerâmica empregada nas formas de metalocerâmica e livres de metal.

2. O envelhecimento artificial acelerado da cerâmica, empregado nas formas de metalocerâmica e livres de metal, proporcionou mudanças insignificantes na cor $(\Delta E<1)$.

3. As pequenas diferenças estatisticamente significantes encontradas em alguns grupos são invisíveis e sem qualquer significado clínico $(\Delta E<3,3)$ 
REFERÊTCIAS BIBLIOGRÁFICAS 


\section{REFERÊNCIAS BIBLIOGRÁFICAS}

ALMILHATTI, H. J.; GIAMPAOLO, E. T.; VERGANI, C. E.; MACHADO, A. L.; PAVARINA, A. C. Shear bond strength of aesthetic materials bonded to $\mathrm{Ni}-\mathrm{Cr}$ alloy. Journal of Dentistry, v. 31, p. 205-211, 2003.

ANUSAVICE, K. J. Phillips Materiais Dentários. $11^{a}$ ed. Rio de Janeiro: Editora Elsevier Ltda, 2005.

BARGHI, N. Color and glaze: Effects of repeated firings. The Journal of Prosthetic Dentistry, v. 47, n. 4, p. 393-395, Apr. 1982.

BARGHI, N.; GOLDBERG, J. Porcelain shade stability after repeated firing. The Journal of Prosthetic Dentistry, v. 37, n. 2, p. 173-175, Feb. 1977.

BARGHI, N; RICHARDSON, J.T. A study of various factors influencing shade of bonded porcelain. The Journal of Prosthetic Dentistry, v.39, n.3, p.282-4, Mar. 1978.

BELSER, U.C; MAGNE, P; MAGNE, M. Ceramic laminate veneers: continuous evolution of indications. Journal of Esthetic Dentistry, v.9, n.4, p.197-207, 1997.

BERGMAN, B.; NILSON, H.; ANDERSSON, M. A longitudinal clinical study of Procera ceramic-veneered titanium copings. The International Journal of Prosthodontics, v. 12, p. 135-139, 1999.

BOLT, R. A.; TEN BOSCH, J. J.; COOPS, J. C. Influence of window size in smallwindow colour measurements, particularly of teeth. Physics in Medicine and Biology, v. 39, p. 1133-1142, 1994.

BREWER, J.D; AKERS, C.K; GALARPO, D.A; SORENSEN, S.E. Spectrometric analysis of the influence of metal substrates on the color of metal-ceramic restorations. Journal of Dental Restorative, v.64, n.1, p.74-7, Jan. 1985.

BREWER, J.D; GALARPO, D.A; CHIPPS, E.A; TEDESCO, L.A. Clinical discrimination between autoglazed and polished porcelain surfaces. The Journal of Prosthetic Dentistry, v.64, n.6, p.631-4, Dec. 1990. 
BREWER, J.D; GLENNON, J.S; GALARPO, D.A. Spectrophotometric analysis of a nongreening metal-fusing porcelain. The Journal of Prosthetic Dentistry, v.65, n.5, p.634-41, May. 1991.

BRIDGEMAN, I. The nature of light and its interaction with matter. In: McDonald R, editor. Colour Physics for Industry. Huddersfield: $H$. Charlesworth \& Co Ltd; 1987, p. 1-34.

CLARK, E. B. An Analysis of Tooth Color. Journal of the American Dental Association, 18:2093, 1931

CRAIG, R. G.; POWERS, J. M. Materiais Dentários Restauradores. $11^{a}$ ed. São Paulo: Livraria Santos Editora Ltda., 2004.

CRISPIN, B. J.; SEGHI, R. R.; GLOBE, H. Effect of different metal ceramic alloys on the color of opaque and dentin porcelain. The Journal of Prosthetic Dentistry , v. 65, n. 3, p. 351-356, Mar. 1991.

CULPEPPER, W.D. A comparative study of shade-matching procedures. The Journal of Prosthetic Dentistry, v.24, n.2, p.166-73, Aug. 1970.

DOUGLAS, R. D. Precision of in vivo colorimetric assessments of teeth. The Journal of Prosthetic Dentistry, v. 77, p. 464-470, 1997.

ERTAN, A. A.; SAHIN, E. Colour stability of low fusing porcelains: an in vitro study. Journal of Oral Rehabilitation, v. 32, p. 358-361, 2005.

EVANS, D.B; BARGHI, N; MALLOY, C.M: WINDELER, A.S. The influence of condensation method on porosity and shade of body porcelain. The Journal of Prosthetic Dentistry, v.63, n.4, p.380-9, Apr. 1990.

FAUNCE, F. Management of discolored teeth. Dental Clinics of North America, v.27, n.4, p.657-70, Oct. 1983.

FERREIRA, D; MONARD, L.A. Measurement of spectral reflectance and colorimetric properties of Vita shade guides. The Journal of the Dental Association of South Africa, v.46, n.2, p.63-5, Feb. 1991.

FRADEANI, M. Six-year follow-up with Empress veneers. The International Journal of Periodontics \& Restorative Dentistry, v.18, n.3, p.216-25, Jun. 1998. 
GOODKIND, R.J; KEENAN, K.M; SCHWABACHER, W.B. A comparison of Chromascan and spectrophotometric color measurements of 100 natural teeth. The Journal of Prosthetic Dentistry, v.53, n.1, p.105-9, Jan. 1985.

GOODKIND, R.J; SCHWABACHER, W.B. Use of a fiber-optic colorimeter for in vivo color measurements of 2830 anterior teeth. The Journal of Prosthetic Dentistry, v.58, n.5, p.535-42, Nov. 1987.

GROH, C.L; O'BRIEN, W.J; BOENKE, K.M. Differences in color between fired porcelain and shade guides. The International Journal of Prosthodontics, v.5, n.6, p.510-14, Nov-Dec. 1992.

HAMMAD, I., A.; STEIN, R., S. A qualitative study for the bond and color of ceramometals. Part II. The Journal of Prosthetic Dentistry, v. 65, n. 2, p. 169179, Feb. 1991.

HASELTON, D.R; DIAZ-ARNOLD, A.M; HILLIS, S.L. Clinical assessment of high-strength all-ceramic crowns. The Journal of Prosthetic Dentistry, v.83, n.4, p.396-401, Apr. 2000.

HERZBERG, T.W; GETTLEMAN, L; WEBBER, R.L; MOFFA, J.P. Effect of metal surface treatment on the masking power of opaque porcelain. Journal of Dental Restorative, v.51, n.2, p.468-72, Mar-Apr. 1972.

HEYDECKE, G; ZHANG, F; RAZZOG, M. In vitro color stability of double - layer veneers after accelerated aging. The Journal of Prosthetic Dentistry, v.85, n.6, p.551-7, Jun. 2001.

HILL, A. R. How we see colour. In: McDonald R, editor. Colour Physics for Industry. Huddersfield: H. Charlesworth \& Co Ltd; 1987. p. 211-281.

ISHIKAWA-NAGAI, S; SATO, R; FURUKAWA, K. Using a computer colormatching system in color reproduction of porcelain restorations. Part 1: Application of CCM to the opaque layer. The International Journal of Prosthodontics, v.5, n.6, p.495-502, Nov-Dec. 1992.

ISHIKAWA-NAGAI, S; SATO, R.R; SHIRAISHI, A; ISHIBASHI, K. Using a computer color-matching system in color reproduction of porcelain restorations. Part 3: A newly developed spectrophotometer designed for clinical application. The International Journal of Prosthodontics, v.7, n.1, p.50-5, Jan-Feb. 1994. 
ISHIKAWA-NAGAI, S; SAWAFUJI, F; TSUCHITOI, H; SATO, R.R; ISHIBASHI, K. Using a computer color-matching system in color reproduction of porcelain restorations. Part 2: Color reproduction of stratiform-layered porcelain samples. The International Journal of Prosthodontics, v.6, n.6, p.5227, Nov-Dec. 1993.

JACOBS, S. H.; GOODACRE, C. J.; MOORE, B. K.; DYKEMA, R. W. Effect of porcelain thickness and type of metal-ceramic alloy on color. The Journal of Prosthetic Dentistry, v. 57, n.2, p.138-145, Feb. 1987.

JOHNSTON, W.M; KAO, E.C. Assessment of appearance match by visual observation and clinical colorimetry. Journal of Dental Restorative, v.68, n.5, p.819-22, May. 1989.

JOINER, A. Tooth colour: a review of the literature. Journal of Dentistry, $v$. 32, p. 3-12, 2004.

JOINER, A.; JONES, N. M.; RAVEN, S. J. Investigation of factors influencing stain formation utilizing an in situ model. Advances in Dental Research, v. 9, p. 471-476, 1995.

JORGENSON, M. W.; GOODKIND, R. J. Spectrophotometric study of five porcelain shades relative to the dimensions of color, porcelain thickness, and repeated firings. The Journal of Prosthetic Dentistry, v. 42, n. 1, p. 96-105, Jul. 1979.

JUDD, D. B.; WYSZCKI, G. Color in Business, Science and Industry, ed. 2, New York, 1963, John Wiley \& Sons, Inc., pp. 226.

KIHN, P.W: BARNES, D.M. The clinical longevity of porcelain veneers: a 48 month clinical evaluation. Journal of the American Dental Association, v.129, n.6, p.747-52, June, 1998.

MCLAREN, K. Colour space, colour scales and colour difference. In: MCDonald R, editor. Colour Physics for Industry. Huddersfield: H. Charlesworth \& Co Ltd; 1987, p. 97-115.

MCLAUGHLIN, G. Porcelain veneers. Dental Clinics of North America, v.42, n.4, p.653-6, ix, Oct. 1998. 
MEIJERING, A.C; ROETERS, F.J.M; MULDER, J; CREUGERS, N.H.J. Patients' satisfaction with different types of veneer restorations. Journal of Dentistry, v.25, n.6, p.493-7, Nov. 1997.

MILLEDING, P; HAAG, P; NEROTH, B; RENZ, I. Two years of clinical experience with Procera Titanium Crowns. The International Journal of Prosthodontics, v.11, n.3, p.224-32, 1998.

MILLEDING, P; ÖRTENGREN, U; KARLSSON, S. Ceramic inlay systems: some clinical aspects. Journal of Oral Rehabilitation, v.22, n.8, p.571-80, Aug. 1995.

MILLER, L. Organization color in dentistry. Journal of the American Dental Association, Spec No: 26E - 40E, Dec. 1987.

MOLIN, M: KARLSSON, S. A clinical evaluation of the Optec inlay system. Acta Odontologica Scandinavica, v.50, n.4, p.227-33, Aug. 1992.

MULLA, F.A; WEINER, S. Effects of temperature on color stability of porcelain stains. The Journal of Prosthetic Dentistry, v.65, n.4, p.507-12, Apr. 1991.

MUTLU-SAGESEN, L; ERGUN, G; OZKAN, Y; BEK, B. Color stability of different denture teeth materials: an in vitro study. Journal of Oral Science, v.43, n.3, p.193-205, Sep. 2001.

NICKERSON, D. Color measurement, U. S. Department of Agriculture Misc. Pub. 58, March, 1946, p. 9.

NIXON, R.L. Masking severely tetracycline-stained teeth with ceramic laminate veneers. Practical Periodontics and Aesthetic Dentistry, v.8, n.3, p.227-35, Apr. 1996, quiz37.

O'BRIEN, W.J; BOENKE, K.M; GROH, C.L. Coverage errors of two shade guides. The International Journal of Prosthodontics, v.4, n.1, p.45-50, Jan-Feb. 1991.

O'BRIEN, W.J; HEMMENDINGER, H.; BOENKE, K.M; LINGER, J. B.; GROH, C.L. Color distribution of three regions of extracted human teeth. Dental Materials, v. 13, p. $179-185,1997$.

O'BRIEN, W.J; KAY, K.S; BOENKE, K.M; GROH, C.L. Sources of color variation of firing porcelain. Dental Materials, v.7, n.3, p.170-3, Jul. 1991. 
OKUBO, S.R; KANAWATI, A; RICHARDS, M.W; CHILDRESS, S. Evaluation of visual and instrumental shade matching. The Journal of Prosthetic Dentistry, v.80, n.6, p.642-8, Dec. 1998.

O'NEAL, S. J.; LEINFELDER, K. F., LEMONS, J. E.; JAMISON, H. C. Effect of metal surfacing on the color characteristics of porcelain veneer. Dental Materials, v. 3, p. 97-101, 1987.

PATTERSON, D. Instruments for the measurement of the colour of transparent and opaque objects. In: McDonald R, editor. Colour Physics for Industry. Huddersfiels: H. Charlesworth \& Co Ltd; 1987, p. 35-62.

PEUMANS, M; VAN MEERBEEK, B; LAMBRECHTS, P; VANHERLE, G. Porcelain veneers: a review of the literature. Journal of Dentistry, v.28, n.3, p.163-77, Mar. 2000.

PRESTON, J.D. Current status of shade selection and color matching, Quintessence International, v.16, n.1 , p.47-58, Jan. 1985.

RAGAIN, J. C.; JOHNSTON, M. W. Color acceptance of direct dental; restoratives by human observers. Color Research and Application, v. 25, p. 278$285,2000$.

RAZZOOG, M. E.; LANG, B. R.; RUSSELL, M. M.; MAY, K. B. A comparison of the color stability of conventional and titanium dental porcelain. The Journal of Prosthetic Dentistry, v. 72, n. 5, p. 453-456, Nov. 1994.

REIS, A.C. Envelhecimento artificial acelerado de resinas compostas - análise da superfície e estudo da alteração de cor por meio de colorímetro espectrofotométrico. Faculdade de Odontologia de Ribeirão Preto - Universidade de São Paulo, 2003 (Tese Doutorado).

RUYTER, I. E.; NILNER, K.; MÖLLER, B. Color stability of dental composite resin materials for crown and bridge veneers. Dental Materials, v. 3, p. 246-251, 1987.

SJÖGREN, G; LANTTO, R.; TILBERG, A. Clinical evaluation of all-ceramic crowns (Dicor) in general practice. The Journal of Prosthetic Dentistry, v. 81, p. 277284, 1999. 
SJÖGREN, G; MOLIN, M; DIJKEN, J.V; BERGMAN, M. Ceramic inlays (Cerec) cemented with either a dual - cured or a chemically cured composite resin luting agent. A 2-year clinical study. Acta Odontologica Scandinavica, v.53, n.5, p.32530, Oct. 1995.

SPROULL, R.C. Color matching in dentistry. II. Practical applications of the organization of color. The Journal of Prosthetic Dentistry, v.29, n.5, p.556-66, May. 1973.

SPROULL, R. C. Color matching in dentistry. Part I. The three-dimensional nature of color. The Journal of Prosthetic Dentistry, v. 86, n. 5, p. 453-457, 2001.

SPROULL, R. C. Color matching in dentistry. Part II. Practical applications of the organization of color. The Journal of Prosthetic Dentistry, v. 86, n. 5, p. 458464.

STAVRIDAKIS, M.M; PAPAZOGLOU, E; SEGHI, R.R; JOHNSTON, W.M; BRANTLEY, W.A. Effect of different high-palladium metal-ceramic alloys on the color of opaque porcelain. The Journal of Prosthetic Dentistry, v.9, n.2, p.71-6, Jun. 2000.

STAVRIDAKIS, M.M; PAPAZOGLOU, E; SEGHI, R.R; JOHNSTON, W.M; BRANTLEY, W.A. Effect of different high-palladium metal-ceramic alloys on the color of opaque and dentin porcelain. The Journal of Prosthetic Dentistry, v.92, n.2, p.170-8, Aug. 2004.

TIDEHAG, P; GUNNE, J. A 2-year clinical follow-up study of IPS Empress ceramic inlays. The International Journal of Prosthodontics, v.8, n.5, p.456-60, Sep-Oct. 1995.

TUNG, F. F.; GOLDSTEIN, G. R.; JANG, S.; HITTELMAN, E. The repeatability of an intraoral dental colorimeter. The Journal of Prosthetic Dentistry, v. 88, p. 585-590, 2002.

VAN DER BURGT, T.P; TEN BOSCH, J.J; BORSBOOM, P.C; KORTSMIT, W.J. A comparison of new and conventional methods for qualification of tooth color. The Journal of Prosthetic Dentistry, v.63, n.2, p.155-62, Feb. 1990.

WATTS, A.; ADDY, M. Tooth discolouration and staining: a review of the literature. British Dental Journal, v. 190, n. 6, p. 309-316, Mar. 2001. 
WEE, A.G; MONAGHAN, P; JOHNSTON, W.M. Variation in color between intended matched shade and fabricated shade of dental porcelain. The Journal of Prosthetic Dentistry, v.87, n.6, p.657-66, Jun. 2002.

ZANIN, F. R. Envelhecimento artificial acelerado - influência na alteração de cor e rugosidade superficial de resinas indiretas. Faculdade de Odontologia de Ribeirão Preto - Universidade de São Paulo, 2005 (Dissertação Mestrado).

ZHANG, F.; HEYDECKE, G.; RAZZOOG, M. E. Double-layer porcelain veneers: Effect of layering on resulting veneer color. The Journal of Prosthetic Dentistry, v. 84, n. 4, p. 425-431, Oct. 2000. 